\title{
De poëtica van het verbeelden van geschiedenis op broadcast televisie
}

\author{
DE CASUS VAN Andere Tijden sinds $2000^{7}$
}

\begin{abstract}
In modern society, television is one of the most important media for presenting the past. This article focuses on the poetics of history on television broadcasts in relation to the manner in which these broadcasts present our past as well as our collective memory. This study rebuts criticism of television as a medium for historical accounts by demonstrating how professionals in the field actively display an extensive knowledge and understanding of the past, provide frameworks for the contextualization of audiovisual materials and depth, and apply and operate specific functions of different representation tools in their productions. To gain insight into the way television producers interact with history, this study combines qualitative textual analysis of the broadcasts and an approach from the field of production studies: diverse in-depth interviews and analysis of internal documents. The case study chosen for this research was Andere Tijden, a history program based on archive material and produced by NTR (formerly known as NPS) and VPRO for the Dutch Broadcast Foundation, from 2000 onwards. The case study demonstrates how television producers' mediation of history is an important practice in the search for history and memories and the conservation and presentation thereof. The analysis reveals the possibility of more cohesive poetics with regard to history on broadcast television and offers insight into the objectives, strategies and conventions of television producers. Special attention is paid to the more implicit practices of selection and interpretation of material by television producers as curators of the past. These implicit practices are made explicit on a cultural-historical, institutional and textual level.
\end{abstract}

KeYwords: Audiovisueel archiefmateriaal, Poëtica geschiedenistelevisie, Cultureel erfgoed, Representatie, Productie-context

Televisie refereert constant aan het verleden. Hoewel het medium volgens sommige critici 'niet zo goed is in geschiedenis', ${ }^{2}$ is televisie één van de belangrijkste media voor de verbeelding en kennisoverdracht van het verleden in onze hedendaagse maatschappij. De mede door digitalisering veroorzaakte history boom heeft een groeiende academische interesse teweeggebracht in de rol van media in het representeren van het verleden, ${ }^{3}$ en televisie als geschiedenisleraar in het bijzonder. ${ }^{4}$ Maar hoe kunnen wij de interactie van televisiemakers met het verleden en herinneringen nader duiden? Aan wat voor voorwaarden dient een bepaalde geschiedenis bijvoorbeeld te voldoen om gevisualiseerd te worden op televisie? En wat zijn de doelstellingen, 
strategieën en conventies van televisiemakers bij het produceren van geschiedenisverhalen? Om dit soort vragen te kunnen beantwoorden, is nader inzicht nodig in de poëtica en het maakproces van televisieprogramma's over geschiedenis. In dit artikel staat daarom de poëtica van geschiedenis op broadcast televisie centraal, in relatie tot de wijze waarop zulke programma's ons verleden en collectief geheugen verbeelden.

Dit onderzoek weerlegt de kritiek op televisie als geschiedenispraktijk door te laten zien hoe televisieprofessionals actief kennis en begrip van het verleden aanbrengen, kaders voor contextualiseren van audiovisueel materiaal en verdieping bieden, en specifieke functionaliteiten van verschillende representatiemiddelen inzetten en sturen in hun producties. 'Geschiedenis', de oneindige dialoog tussen het heden en het verleden, werd oorspronkelijk gedefinieerd als een continu proces van interactie tussen de historicus en zijn (haar) feiten. ${ }^{5}$ Echter, mede door de groeiende en wijdverspreide functie van media in onze hedendaagse cultuur, heeft de historicus het alleenrecht op het definiëren en representeren van het verleden uit handen moeten geven, zoals Aleida Assmann het ook stelt: "What is called the "memory boom" is the immediate effect of this loss of the historian's singular and unrivalled authority. ${ }^{6}$ Geschiedenistelevisie als verbeelding van het verleden is hier een voorbeeld van en bestaat uit een complexe constellatie van dynamische praktijken. Een combinatie van onderzoeksmethodes is daarom ingezet om recht te kunnen doen aan deze complexiteit.

Om de poëtica van makers met betrekking tot het verbeelden van geschiedenis op televisie in kaart te brengen, pleit ik voor een dubbele aanpak: een kwalitatieve tekstanalyse van programma's in combinatie met een benadering afkomstig uit het veld van productiestudies: diverse diepte-interviews met makers en de analyse van interne productiedocumentatie. Binnen het televisiewetenschappelijk onderzoek - waar studies naar bijvoorbeeld genre en receptie worden uitgevoerd - is meer aandacht voor de analyse van programma-inhoud in combinatie met productiestudies nodig. Televisie is immers een complexe constellatie van dynamische praktijken en om de inhoud van programma's als 'tekst' beter te kunnen duiden is een samenhangende reflectie op de rol van televisiemakers als industrial actors - dat wil zeggen, hoe makers actief televisie-inhoud selecteren en vormgeven - uiterst relevant.7 Een dergelijke aanpak kan mediaonderzoekers bovendien helpen bij het beter begrijpen van de inhoud én productie van broadcast televisie als processen van double mediation: televisiemakers observeren en heroriënteren vragen en zorgen uit de maatschappij, door deze terug te projecteren op de samenleving in de herkenbare vorm van een televisieprogramma. ${ }^{8}$

Dit alles roept de vraag op hoe bronnen en verhalen over historische en voorbije gebeurtenissen worden verzameld, gereconstrueerd en gevisualiseerd door televisiemakers, en wat voor soort geschiedenis deze makers creëren op broadcast televisie. Deze vraag zal onderzocht worden aan de hand van de casus van het Nederlandse televisieprogramma Andere tijden (NPS/NTR/VPRO, 200o-heden). ${ }^{9}$ Hieronder zal de methodologische aanpak (\$I) en de gekozen casus $(\mathbb{2} 2)$ toegelicht worden. De analyse onthult vervolgens verschillende tekstuele, cultuurhistorische en institutionele doelstellingen, strategieën en conventies voor het verbeelden van geschiedenis op broadcast televisie:

- Ten eerste wordt op een institutioneel niveau op de productiecontext gereflecteerd ( $(\sqrt[3]{3})$, namelijk: in hoeverre er wekelijks aandacht aan geschiedenis op de Nederlandse 


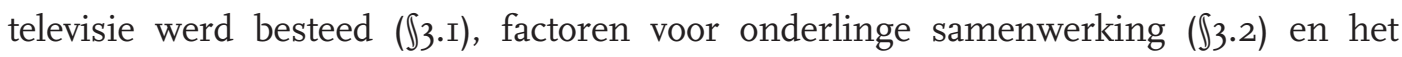
creëren van een huisstijl ( $(\mathbb{3} \cdot 3)$;

- Ten tweede worden de selectie en reconstructie van historische gebeurtenissen in Andere tijden in een breder cultuurhistorisch kader geplaatst ( $\left(\mathbb{4}_{4}\right)$;

- Ten derde worden de verschillende tekstuele en narratieve conventies, strategieën en doelstellingen van het programma onder de loep genomen $(\sqrt{5})$, in het bijzonder: de rol van de presentator ( $(\mathbb{5} 5$.I), het hergebruik van archiefmateriaal $(\mathbb{5} 5.2)$, ooggetuigenverslagen en herinneringspraktijken ( $(\mathbb{5} .3)$ en drama / re-enactment $(\mathbb{5} 5.4)$;

- Ter afsluiting zal gereflecteerd worden op voor televisie bijzondere cultuurhistorische vraagstukken bij het representeren van geschiedenis (\$6), namelijk: de rol van historici

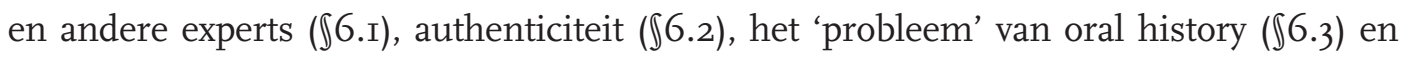
het aanspreken van een specifieke doelgroep (\$6.4).

Op deze wijze kan aan de hand van een casus inzicht worden gegeven in de poëtica en overwegingen van televisiemakers ten aanzien van geschiedenis en herinneringen - daarbij worden in het bijzonder de doorgaans meer impliciete praktijken van selectie en interpretatie door televisiemakers als curatoren van het verleden expliciet gemaakt.

\section{Methodologie: poëtica en de constructie van betekenis}

In dit onderzoek verricht ik een kwalitatieve tekstanalyse van televisieprogramma's in combinatie met een productiestudies benadering. In navolging van Ann Gray en Erin Bells project 'Televising History I995-2010'10 ben ik hoofdzakelijk geïnteresseerd in het analyseren hoe televisie geschiedenis verbeeldt en wat voor soort geschiedenis televisiemakers creëren. ${ }^{\text {II }}$ Ik leg daarom de nadruk op de poëtica van televisiegeschiedenis op broadcast televisie als onderzoekskader om inzicht te verkrijgen in het maakproces, de daarbij behorende conventies, strategieën en doelstellingen, en de mogelijke gevolgen van deze keuzes. David Bordwell vat deze benadering als volgt kort samen:

The poetics of any artistic medium studies the finished work as the result of a process of construction - a process that includes a craft component (such as rules of thumb), the more general principles according to which the work is composed, and its functions, effects, and uses. Any inquiry into the fundamental principles by which artifacts in any representational medium are constructed, and the effects that flow from those principles, can fall within the domain of poetics. ${ }^{\mathrm{I2}}$ (Mijn cursivering; $\mathrm{BH}$ )

Zoals Bordwell heeft aangetoond is onderzoek naar poëtica vooral een manier van vragen stellen en bovenal de overkoepelende vraag: hoe werkt dit? Specifieke criteria en aandachtspunten die centraal dienen te staan bij de analyse van het verzamelde onderzoeksmateriaal (televisieprogramma's; diepte-interviews; productie-documentatie) bij het onderzoek naar de poëtica van televisiegeschiedenis op broadcast televisie, zijn daarom:

- Welke beelden en verhalen uit het verleden zijn geselecteerd (en door wie/op welke wijze/waarom/met welk gevolg), en welke niet? 
- Wat zijn de materialen en verhalende vormen van geschiedenistelevisie (en ingezet door wie/op welke wijze/waarom/met welk gevolg), en wat niet?

- Hoe zetten makers welke representatiemiddelen in, bijvoorbeeld montage, archiefmateriaal, presentator, ooggetuigen, experts, drama... (en door wie /waarom/met welk gevolg), en welke niet?

- Welke strategieën voor plausibiliteit en het contextualiseren van de historische beelden en verhalen worden gebruikt (en door wie/op welke wijze/waarom/met welk gevolg), en welke niet?

- In welke conventies (formats, huisstijlen, (on)bewuste praktijkmethodes) zijn deze beslissingen gegrond (en door wie/op welke wijze/waarom/met welk gevolg), en welke niet?

Een reflectie op de rol van televisiemakers en hoe zij actief televisie-inhoud vormgeven, is noodzakelijk bij een onderzoek naar poëtica. In het kader van dit onderzoek zijn daarom volgens een aanpak uit het onderzoeksveld van productiestudies semigestructureerde diepteinterviews (met een lijst van open vragen) uitgevoerd en getranscribeerd. In sommige gesprekken kwam op bepaalde momenten interne productiedocumentatie ter sprake. Productiedocumentatie is ook verzameld en geanalyseerd. Interviews en persoonlijke communicatie vonden plaats in de periode mei 20II-maart 2017 met de volgende aan 'Andere tijden' gelieerde televisieprofessionals: Karin van den Born; Hein Hoffmann; Gerda Jansen Hendriks; Ad van Liempt en Lizzy van Winsen. Hierbij is het belangrijk om op te merken dat één televisieprofessional vaak meerdere en uiteenlopende verantwoordelijkheden of taken bij de productie van een televisieprogramma heeft doorlopen en kan bespreken en ook vaak meerdere en verschillende producties binnen de 'Andere tijden-school' heeft gemaakt. Sommige professionals zijn ook meerdere malen geïnterviewd over een langere periode.

In samenhang met een productiestudies aanpak, kan een kwalitatieve tekstanalyse van een relevante audiovisuele casus een belangrijke bijdrage leveren in mediaonderzoek naar processen van betekenisgeving. De tekstanalyse is uitgevoerd aan de hand van bijna I30 geselecteerde Andere tijden afleveringen tussen maart 2000 en mei 2015 - zie de bijlage voor een complete lijst. ${ }^{13}$ Volgens Glen Creeber voorziet een tekstanalyse onderzoekers van 'een vorm en een taal aan de hand waarvan mogelijke uitkomsten van manipulatie geanalyseerd en bediscussieerd kunnen worden. ${ }^{\text {I4 }}$ Ik volg hierbij Lisa Gitelmans argumentatie om de voorkeur te geven aan de analyse van een casus: 'Media (...) are very particular sites for very particular, importantly social as well as historically and culturally specific experiences of meaning. For this reason, the primary mode (...) is the case study'. ${ }^{15}$ Kort gezegd, specifieke casussen kunnen weer specifieke aspecten van de representatie van geschiedenis op televisie toelichten.

\section{De casus Andere tijden}

Andere tijden ${ }^{\mathrm{I}}$ is een op archiefmateriaal gebaseerd geschiedenisprogramma geproduceerd door NTR (voorheen NPS) en VPRO voor de Nederlandse publieke omroep. Het programma kan het beste worden omschreven als een actueel historisch magazine. ${ }^{17}$ Het uitgangspunt van het programma is, ook in vergelijking met internationale productiecontexten (zowel publiek als commercieel), bijzonder: '(...) 35 uitzendingen per jaar met een min of meer actuele aanleiding, 
zodat aan het begin van een begrotingsjaar absoluut niet te zeggen is waar de uitzendingen over zullen gaan. ${ }^{\text {I8 }}$ Het programma verdiept zich in één historisch onderwerp per aflevering van ongeveer dertig minuten. ${ }^{\text {I9 }}$ Als geschiedenisprogramma is Andere tijden het enige in zijn soort in Nederland door hedendaagse gebeurtenissen als uitgangspunt te nemen. Een noemenswaardige link met het heden bepaalt de keuze van de historische onderwerpen. Onderwerpen zijn opmerkelijk doordat ze zich op de actualiteit betrekken, een onbekend verhaal vertellen, nieuwe feiten brengen of nog nooit in Nederland vertoonde beelden bevatten. Het format streeft er op deze wijze naar om lopende zaken met nieuwe inzichten te verrijken en historische gebeurtenissen te relativeren.

Historische gebeurtenissen uit de twintigste eeuw worden uiteengezet door middel van audiovisueel archiefmateriaal en er wordt door middel van interviews met betrokkenen teruggeblikt op een gebeurtenis die verband houdt met het heden. Vanaf de eerste uitzending op I2 maart 2000 wordt Andere tijden gepresenteerd door historicus Hans Goedkoop, sinds november 2006 vanuit het gebouw van het Nederlands Instituut voor Beeld en Geluid in Hilversum. In een coproductie van NOS en VPRO wordt vanaf voorjaar 2008 onder hetzelfde format een sporteditie geproduceerd onder de naam Andere tijden sport (NPS/NOS/VPRO, 2008-heden). Vanuit het Olympisch Stadion in Amsterdam presenteert en (via voice-over) becommentarieert sportjournalist Tom Egbers historische en memorabele sportonderwerpen. Het programma stond bovendien aan de wieg van crossmediale vertelvormen. In de periode I999-2000 bedongen de programmamakers een begeleidende website als voorwaarde bij het televisieprogramma. De televisiehistoriografische benadering van de serie kwam ook tot uiting in gerelateerde multimedia zoals de programmawebsite, waarin niet alleen extra achtergrondinformatie en onderzoeksmateriaal, maar ook bronnenkritiek en -annotatie verwerkt werd. ${ }^{20}$ Voor het onderzoek naar en het uitzenden van historische gebeurtenissen heeft Andere tijden verschillende prijzen ontvangen, waaronder de prestigieuze Zilveren Nipkowschijf.

In het tweede jaar op broadcast televisie bereikt Andere tijden een kijkcijfer-resultaat van 640.000 kijkers. ${ }^{21}$ In 2004 wordt de jaarlijkse Andere tijden special bekeken door I.280.000 kijkers, met een waarderingscijfer van 8,5 . Het programma blijft goed bekeken met tussen de 673.000 en 867.000 kijkers voor de meest populaire afleveringen tussen 2005 en 2010 en hoge waarderingscijfers variërend tussen de 7,6 en $8,3 .{ }^{22}$ Andere tijden sport trekt door de jaren heen steeds meer kijkers met gemiddelden tussen de 800.000 en I.000.000, ${ }^{23}$ en zeer goed bekeken afleveringen zoals "Hilbert van der Duim, meer dan een clown" (NOS/VPRO, 9 januari 2OII, I.327.000 kijkers); "WK ‘78: door andere ogen” (NOS/VPRO, 6 juli 20I4, I.400.000 kijkers ${ }^{24}$ ); en "De teruggevonden Elfstedentocht" (NOS/VPRO, I2 januari 20I4, I.532.000 kijkers ${ }^{25}$ ). In 2OI5 behaalt de Andere tijden aflevering "De gouden jaren van Heintje" (NTR/VPRO, I2 januari 20I5), over het jeugdfenomeen Heintje, rond een miljoen kijkers. ${ }^{26}$ In 2017 is de best bekeken aflevering op het moment van schrijven de Andere tijden sport aflevering "Jannes van der Wal: de onbegrepen dammer" (NOS/VPRO, 29 januari 20I7) met een kijkdichtheid van 7,8, een marktaandeel van 2I,3 en een absoluut aantal kijkers van I.2I8.000, ${ }^{27}$ en in $20 \mathrm{I} 7$ is de best beoordeelde Andere tijden aflevering op het moment van schrijven "Het einde van het Waterlooplein?” (NTR/VPRO, 2I januari 20I7) met een waarderingscijfer van 8,I (573.000 kijkers). ${ }^{28}$ Om dit in perspectief te plaatsen: er zijn 7.72I particuliere huishoudens in Nederland, met gemiddeld I,6 televisies per huishouden. ${ }^{29}$ 


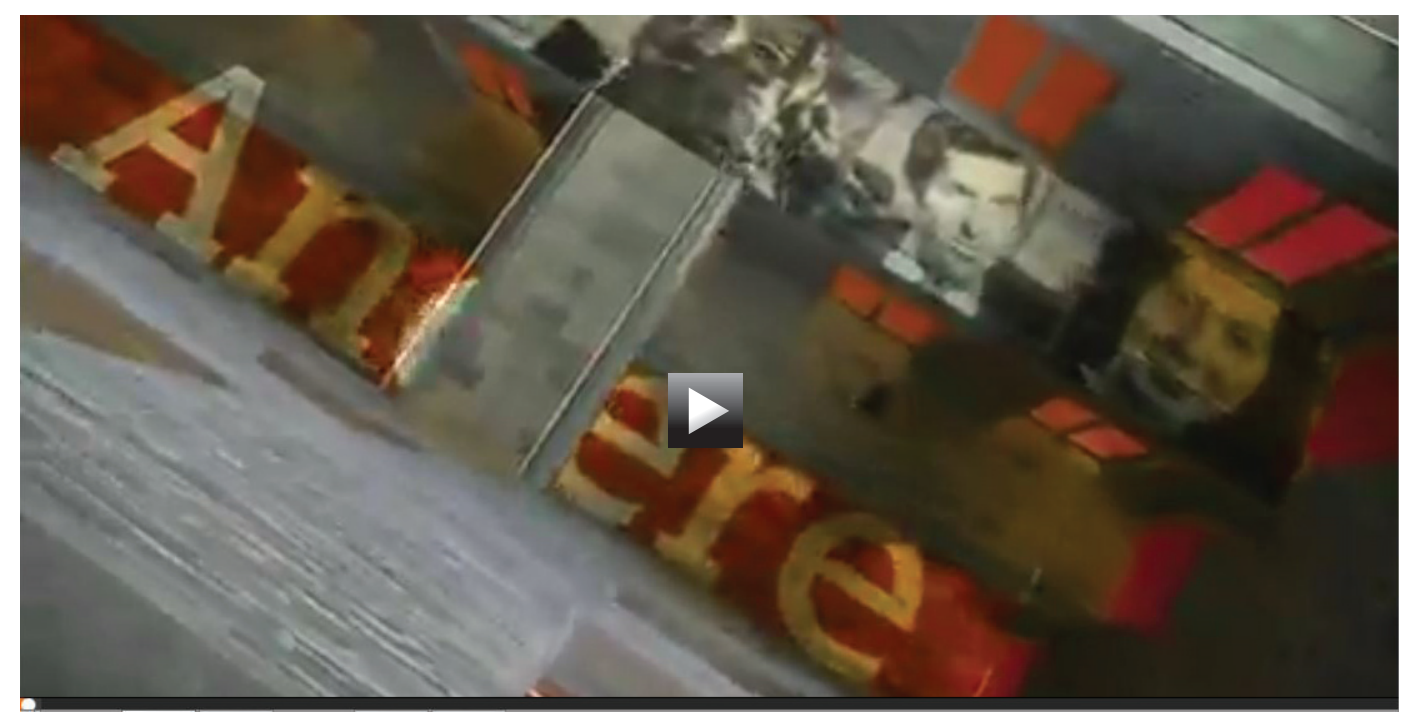

Andere tijden aflevering "Het einde van het Waterlooplein?" (NTR/VPRO, 21 januari 2017).

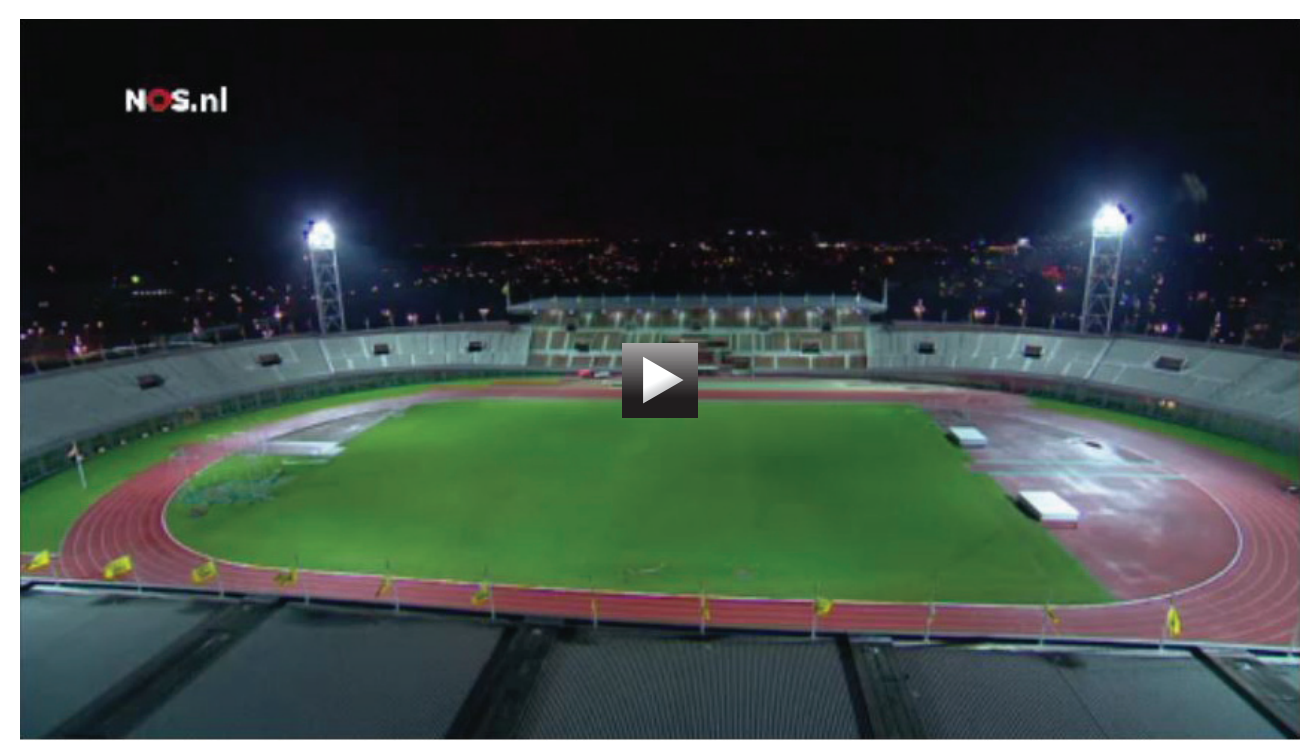

Andere tijden sport aflevering "De teruggevonden Elfstedentocht” (NOS/VPRO, 12 januari 2014).

\section{Institutionele doelstellingen, strategieën en conventies: de productiecontext}

In mijn proefschrift Doing History, Creating Memory toon ik de rol aan van de Nederlandse televisie-industrie en de publieke omroep als pionier en experimentele ruimte in de ontwikkeling van Andere tijden en soortgelijke programma's sinds 2000, eveneens als gevolg van samenwerking tussen NPS/NTR en VPRO. ${ }^{30}$ Zo'n samenwerking was echter niet vanzelfsprekend, zoals blijkt uit de productiecontext en ontstaansgeschiedenis van Andere tijden.

\subsection{Een hoekje voor het verleden}

In 1992 hekelt historicus en programmamaker (voor NOS/NPS/NTR) Gerda Jansen Hendriks het ontbreken van een traditie van permanente, langdurige geschiedenisprogrammering op de Nederlandse televisie. In een vroege programmaopzet formuleert zij deze uitspraak: 
[E]r is op Nederlandse televisie geen traditie van historische programma's. Er zijn af en toe documentaires, er is af en toe een serie. Maar er is niets dat lijkt op rubrieken als Damals (ZDF) of Timewatch (BBC). Het buitenland doet het lang niet altijd beter dan Nederland, maar waarom zou er hier geen gebruik worden gemaakt van de vele schatten in film-, televisie- en radioarchieven, van de mooie verhalen die mensen kunnen vertellen, van de behoefte om wat meer over het recente verleden te weten? ${ }^{31}$

Er gaan in deze periode meer geluiden op dat in Nederland niet genoeg zendtijd wordt besteed aan geschiedenis. In 1998 duidt cultuurredacteur Raymond van den Boogaard in NRC handelsblad deze behoefte aan wekelijkse aandacht voor het verleden op de Nederlandse publieke omroep als volgt:

De Nederlandse televisie doet zo weinig aan geschiedenis, dat het soms lijkt alsof Nederland en de rest van de wereld pas gisteren zijn uitgevonden. Een regelmatig terugkerend geschiedenisprogramma achten de Hilversumse bedenkers kennelijk te hoog gegrepen voor ons volk. (...) Zou er nu echt geen hoekje zijn voor een historisch programma, tussen al die medische programma's en uitzendingen over ethische vraagstukken over drie zenders publieke televisie? (...) Het verleden staat niet stil - buiten Nederland. ${ }^{32}$

\subsection{Samenwerking op televisieniveau?}

Eindredacteur en medebedenker Ad van Liempt heeft het geschiedenisprogramma Andere tijden omschreven als een lang gekoesterde wens van NPS-collega's als Gerda Jansen Hendriks, Carla Boos en Van Liempt zelf. Na zijn adviserende rol bij het grootschalige documentaireproject $\mathrm{Na}$ de oorlog (NPS, 1995) en de geschiedenis-documentaireserie De affaire (NPS, 1999) staat het voor hem vast dat continuiteit de belangrijkste basis voor een geschiedenisdocumentaire is. Hij verwoordt de problemen die destijds werden veroorzaakt door het ontbreken van een afdeling geschiedenis bij de Nederlandse publieke omroep:

[E]lke keer als de serie was afgelopen dan ging de club weer uit elkaar. Iedereen ging zijns weegs en als er dan weer een volgend programma begon, moest alles opnieuw worden uitgevonden. Er was geen lijn, geen stijl, geen archief, geen personeel. Alles moest elke keer opnieuw. ${ }^{33}$

In 1999 besluiten de Nederlandse Programma Stichting (NPS) en VPRO om een wekelijks televisieprogramma over geschiedenis op poten te gaan zetten. Van Liempt prijst hierbij Carel Kuyl, in I999 aangesteld als programmadirecteur voor de NPS, voor het geven van toestemming om door te gaan. Gezien de grote mate van vertrouwen die nodig is om het programma te maken, kan ook Van Liempts eigen status binnen de Nederlandse televisie-industrie worden gezien als een belangrijke factor bij deze beslissing. Het toenmalige geschatte budget (aantal personeelsleden, verwachte uitzendtijd) maakt het mogelijk om slechts twee keer per jaar I3 afleveringen uit te zenden. Dit zou een 'gat' opleveren van I3 weken geen geschiedenis op televisie. 
De redactieleden van Andere tijden zijn echter van mening dat geschiedenis een continu proces is en dat geschiedenis herhaaldelijk moet worden uitgezonden op televisie. Bovendien heeft het team al de formule bedacht waarbij actualiteit het centrale uitgangspunt vormt. Hans Maarten van den Brink, op dat moment programmadirecteur van VPRO televisie, wordt benaderd met een voorstel tot samenwerking. De VPRO is dan al het historische radioprogramma OVT aan het uitzenden, en een samenwerking op televisie-niveau lijkt een logisch vervolg. Van Liempt herinnert zich het beslissende gesprek met Van den Brink over de samenwerking tussen de NPS en VPRO als volgt:

Dus sprak hij [Van den Brink] wat mij betreft de historische woorden: 'Ik ben eigenlijk tegen samenwerking op programmaniveau, maar dit is zo'n goed idee dat ik hier geen nee tegen kan zeggen.' Maar hij zei er wel bij, dat hij eigenlijk ontzettend de pest in had, dat het niet uit zijn eigen organisatie was gekomen. Dat hadden ze natuurlijk gewoon zelf moeten bedenken. Ze deden toen al tien jaar OVT of zo, maar er was niemand bij hem gekomen van: 'zullen we dit eens op televisie gaan doen?'34

Binnen het Nederlandse publieke omroepbestel levert samenwerking tussen omroepen en op verschillende mediaplatformen regelmatig problemen op. Het succes van Andere tijden lijkt echter grotendeels voort te komen uit het coöperatieve karakter van het programma.

\subsection{De huisstijl 'binnenshuis' houden}

Tijdens mijn gesprekken met de makers van Nederlandse geschiedenisprogramma's stipten zij zelf regelmatig het belang aan van hun eigen jarenlange ervaring en deskundigheid bij het bedenken, regisseren en uitvoeren van onderzoek voor geschiedenisprogramma's, zoals het traceren en evalueren van bronmateriaal en ooggetuigen. Het lijkt erop dat kennis en knowhow van essentieel belang zijn bij het maken van geschiedenisprogramma's voor televisie. Het produceren van een langlopende televisieserie betekent jaren achtereen hetzelfde soort werk uitvoeren. Televisiemakers uit de "Andere tijden-school" wisselen daarom regelmatig van programma en houden zich met uiteenlopende historische praktijken bezig, wat programmamakers nieuwe inzichten biedt, nieuwe vaardigheden laat ontwikkelen en interne mobiliteit schept. Hierdoor blijft knowhow 'binnenshuis', wat Van Liempt ziet als de sleutel tot het programmeren van geschiedenis:

Expertise in huis houden, dat is eigenlijk het geheim en daarvoor was het ook nodig, dat die mensen niet allemaal na twee jaar weggaan, want dan houd je ook geen expertise. Die is er nu. $\mathrm{Nu}$ zitten er mensen vanaf het begin. D'r zitten ook mensen vijf jaar en zeven jaar, dus er is een schat aan ervaring. Bij geschiedenisprogramma's maken speelt ervaring echt een belangrijke rol. Als je heel snel weet waar je iets kunt vinden, dat werkt natuurlijk veel effectiever, dan wanneer iedereen alles maar vanaf nul moet ontdekken. ${ }^{35}$

Door dezelfde mensen 'aan boord' te houden - en niet alleen voor één seizoen of voor een paar afleveringen per jaar - werd een specifieke 'huisstijl' of 'school' ontwikkeld binnen de 
Nederlandse televisie-industrie met een gemeenschappelijke overtuiging over hoe geschiedenis op televisie te laten zien. Deze Andere tijden-school ontwikkelde zo - zowel direct als indirect een gemeenschappelijke aanpak en kenmerken die continue worden toegepast bij afleveringen van Andere tijden, ook al worden ze gemaakt door verschillende regisseurs. De op feiten gebaseerde aanpak van het programmeren van geschiedenis werd ook het uitgangspunt voor nieuwe geschiedenisprogramma's na Andere tijden, zoals De oorlog (NPS, 2009), 13 in de oorlog (NPS, 2009-2010); De slavernij (NTR, 20II), De gouden eeuw (NTR/VPRO, 20I2-2013), Na de bevrijding (NTR, 20I4); De ijzeren eeuw (NTR/VPRO, 20I5); Ondersteboven: Nederland in de jaren zestig (NTR/VPRO, 20I6), Goede hoop (NTR, 20I7) en, in samenwerking met andere Europese omroepen, 14-18: dagboeken uit de Eerste Wereldoorlog (NTR/VPRO, 20I4) - met inbegrip van aanvullende crossmediale toepassingen bij deze diverse programma's. Het format van Andere tijden zelf omvat een focus op de geschiedenis van de twintigste eeuw, een link met actuele gebeurtenissen, archiefbeelden en interviews, met een contextueel kader door de presentator. ${ }^{36}$ De bovengenoemde geschiedenisprogramma's leggen noodzakelijkerwijs niet allemaal de nadruk op de geschiedenis van de twintigste eeuw, het hergebruik van archiefbeelden of een link met de actualiteit. Critici complimenteren Andere tijden met het onder de aandacht brengen van geschiedenis op de Nederlandse televisie ${ }^{37}$ en de interesse van televisiekijkers in geschiedenis zou later in het decennium uitgroeien tot een echte 'trend'. ${ }^{8}$

\section{Cultuurhistorische doelstellingen, strategieën en conventies: de selectie en reconstructie van gebeurtenissen in een breder cultuurhistorisch kader}

Hoe bepalen programmamakers welke historische verhalen te vertellen aan hun publiek? Welke verhalen worden geselecteerd, gereconstrueerd, en in welke mate wordt het verleden herschreven? Televisie maken is een gezamenlijk proces, en in dit creatieve proces is besluitvorming de gebruikelijke procedure. Van regisseur, presentator tot redacteur moeten de makers in verschillende stadia omgaan met keuzes met betrekking tot de selectie en de vertelling van een bepaalde geschiedenis.

Andere tijden is bewust gericht op bijna vergeten verhalen uit de eeuw van het bewegende beeld, de twintigste eeuw. ${ }^{39}$ In haar oorspronkelijke, in 1992 ingediende opzet stelt Jansen Hendriks voor zich te richten op historische gebeurtenissen na 1945 en wel om twee redenen. In de eerste plaats zullen zowel ooggetuigen als beeldmateriaal dan op grote schaal beschikbaar zijn. Ten tweede is de verwachting dat de algemene interesse groter zal zijn voor gebeurtenissen na I945 'dan voor willekeurige onderwerpen uit de achttiende eeuw'. Echter: 'uitzonderingen bevestigen de regel: de jaren dertig worden niet per definitie uitgesloten' ${ }^{40}$ Uiteindelijk wordt besloten om geen historische verhalen van vóór de twintigste eeuw uit te zenden. Niet alleen zijn dergelijke verhalen aanzienlijk moeilijker te produceren, maar de makers zijn van mening dat de beschikbaarheid van audiovisueel archiefmateriaal bij verhalen uit de twintigste eeuw het uitzenden van die historische verhalen veel aantrekkelijker maakt. ${ }^{4 \mathrm{I}}$

Een focus op een specifiek aspect van een bepaalde geschiedenis kan nieuw inzicht in bijna vergeten actuele zaken uit het verleden bieden. Bij voorkeur wordt dit gedaan door de focus te leggen op een specifieke gebeurtenis die staat voor een grotere ontwikkeling. Dit is volgens de makers een heel andere aanpak dan het geven van een breed overzicht dat 
gemakkelijk aanzet tot nostalgie. De aflevering “De 'andere' familie Frank" (NPS/VPRO, 4 mei 2008) bijvoorbeeld geeft door middel van familie-archiefbeelden de ervaring van de Tweede Wereldoorlog weer vanuit het perspectief van de onbekende Joodse familie Frank uit Ochten. ${ }^{42}$ Vergelijkbaar is de aflevering "Een Indische familie" (NPS/VPRO, 5 november 2002) waarin een persoonlijk familierelaas over de oorlog in voormalig Nederlands-Indië symbool komt te staan voor wat mensen ervaren hebben vlak voor, tijdens en na de oorlog. Op deze manier laat de serie zien dat geschiedenis niet alleen uit verhalen van bekende historische figuren en leiders bestaat.

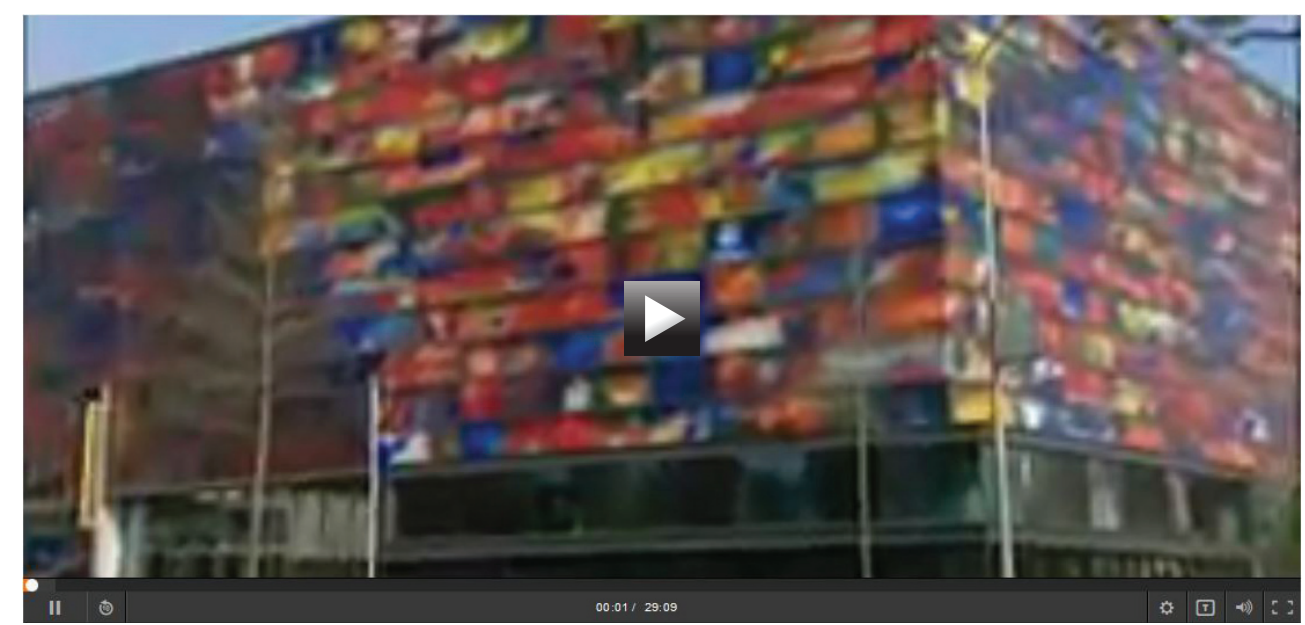

Andere tijden aflevering "Koerier voor Portugal" (NTR/VPRO, 12 mei 2013).

Door de jaren heen is er een toename waar te nemen (zie Tabel i) van nationale geschiedenisverhalen ten opzichte van thema's met een internationale focus: bij aanvang van het programma in 2000 bevatte $62 \%$ van de afleveringen een historische thema met een nationale focus terwijl dit in 2015 rond de $76 \%$ was. Een voorbeeld van een historisch thema met een 'nationale' (Nederlandse) focus is de aflevering "De komst van de moskee" (NPS/VPRO, I februari 2005), terwijl onder een thema met een 'internationale' focus bijvoorbeeld de aflevering "Koerier voor Portugal" (NTR/VPRO, I2 mei 20I3) valt. Opvallend is dat in het jaar 20I6, een jaar waarin veel disruptieve 'media events' op internationaal niveau de boventoon voerden (onder meer de 'Brexit', de campagne van Donald Trump als Republikeinse presidentskandidaat tijdens de verkiezingen in de Verenigde Staten en meerdere terroristische aanslagen in diverse landen), deze verschuiving lijkt te zijn omgekeerd: het aandeel internationale onderwerpen is bijna verdubbeld ten opzichte van het voorgaande jaar.

De programmamakers spannen zich in om een steeds breder scala aan onderwerpen uit te kunnen zenden. Recente gebeurtenissen functioneren eerder als een uitgangspunt voor Andere tijden dan dat ze een expliciete vergelijking met het heden maken. Actuele gebeurtenissen als uitgangspunt nemen is in de woorden van de makers een enigszins 'rekbaar begrip' en open voor interpretatie. Locatie is geen doorslaggevende factor voor een 'internationale' of 'nationale' focus: bijvoorbeeld, de verkiezingen in Suriname zijn het uitgangspunt voor "Bouterse, het Haagse hoofdpijndossier" (NTR/VPRO, I9 mei 20I5), maar de aflevering gaat hoofdzakelijk 


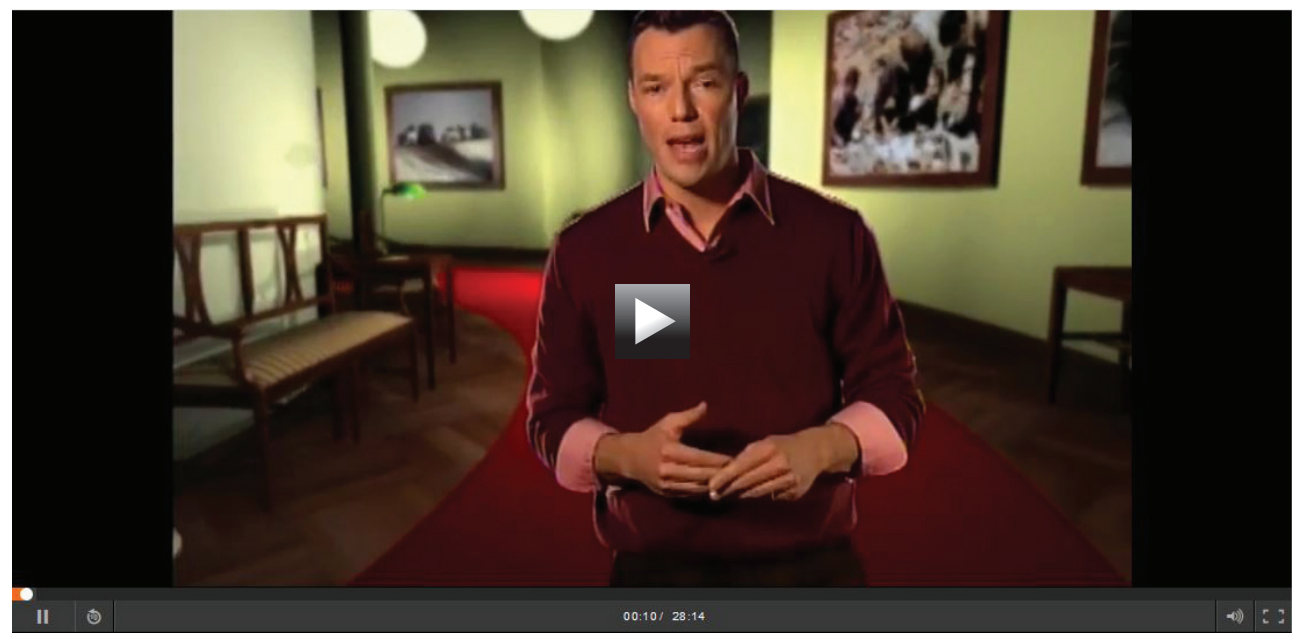

Andere tijden aflevering "De komst van de moskee" (NPS/VPRO, 1 februari 2005).

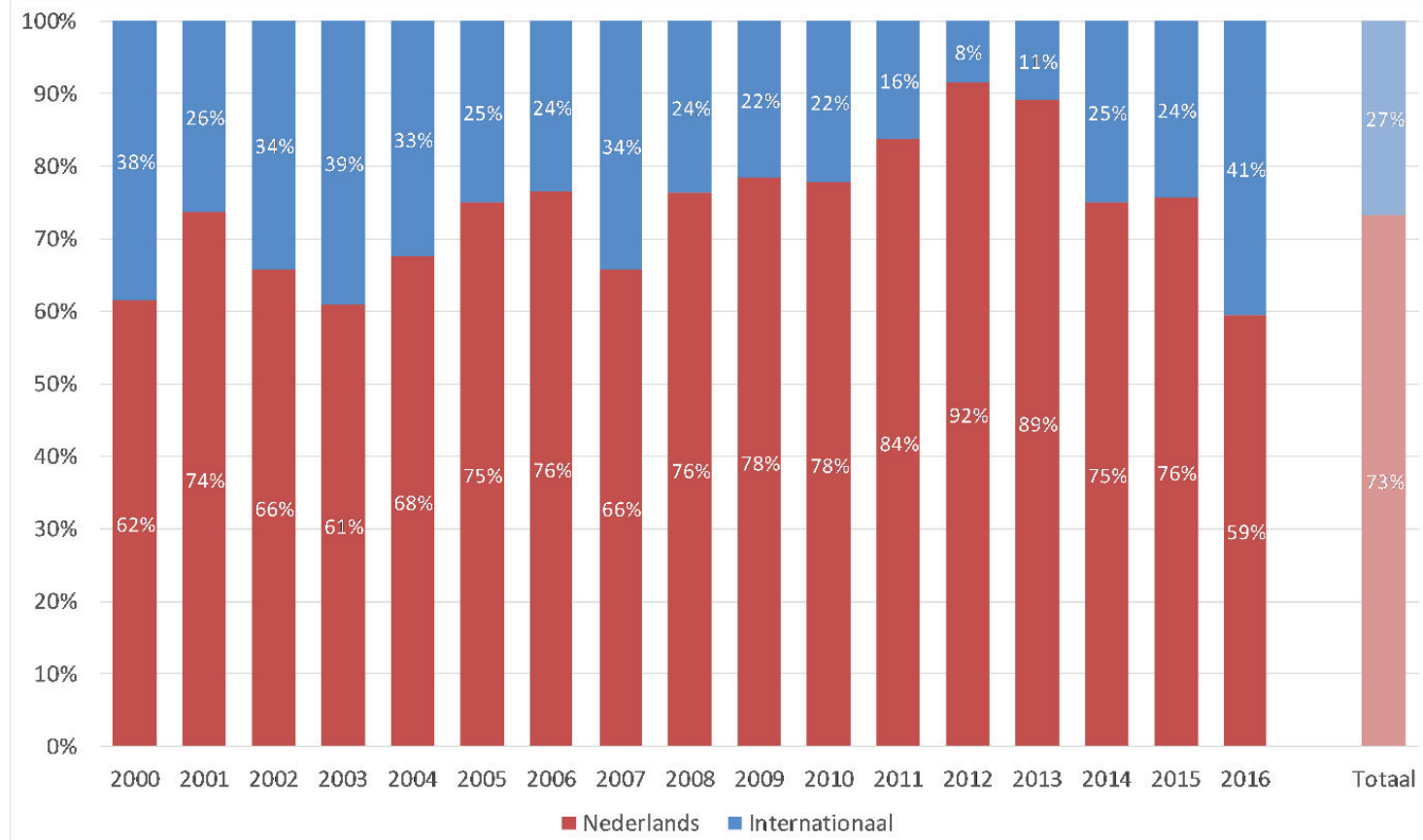

Tabel I. Verhouding algemene thema's met een internationale focus t.o.v. thema's met een nationale Nederlandse focus in Andere tijden afleveringen per jaar tussen maart 2000 en december 2016.43

over Nederlandse politiek en onrust in Den Haag over Dési Bouterse. De waargenomen verschuiving naar meer nationale onderwerpen lijkt geen bewust beleid. Er kunnen verschillende mogelijke aanleidingen genoemd worden: van de populariteit van Nederlandse onderwerpen onder kijkers tot de praktische omstandigheid dat minder budget betekent dat een nog groter deel van de beschikbare audiovisuele materialen geselecteerd is uit de archieven van het Nederlands Instituut voor Beeld en Geluid en dat er minder mogelijkheden zijn om materiaal uit het buitenland aan te kopen of in het buitenland te filmen.

Andere tijden heeft door de jaren heen niet radicaal afgeweken van het programmaformat sinds het begin in 2000, maar er is in de poëtica hier en daar een verandering in nuance waar te nemen. Hoewel het programma begon met meerdere historische onderwerpen per aflevering, verschoof de focus al snel naar één historisch thema per aflevering. 
Dit heeft zeker invloed op het soort verhalen dat er over het verleden verteld kunnen worden - en op wat voor manier - binnen het tijdsbestek van één aflevering. Volgens Karin van den Born, NTR programmamaker en sinds 2007 eindredacteur van Andere tijden, heeft de oorspronkelijke opzet stand gehouden. Er is echter een verschuiving in nuances te zien waar het de selectie en reconstructie van historische verhalen betreft. Zo heeft Van den Born (per I januari 2017 opgevolgd door Marja Ros, de huidige eindredacteur van Andere tijden; Van den Born is inmiddels eindredacteur Televisie bij NTR) bijvoorbeeld een persoonlijke interesse in meer sociale onderwerpen, zoals de zorg. De eindredacteur streeft echter naar een balans tussen politieke en culturele onderwerpen. Waar een paar jaar geleden een aflevering over de Tweede Wereldoorlog nog een standaard 'hit' bij kijkers was, ligt het vandaag de dag veel meer aan het onderwerp of een aflevering een succes is. ${ }^{44}$ Zie figuur I en 2 voor een overzicht van de algemene historische thema's in Andere tijden afleveringen tussen maart 2000 en december 2016 - met achtereenvolgens een internationale en een nationale focus.

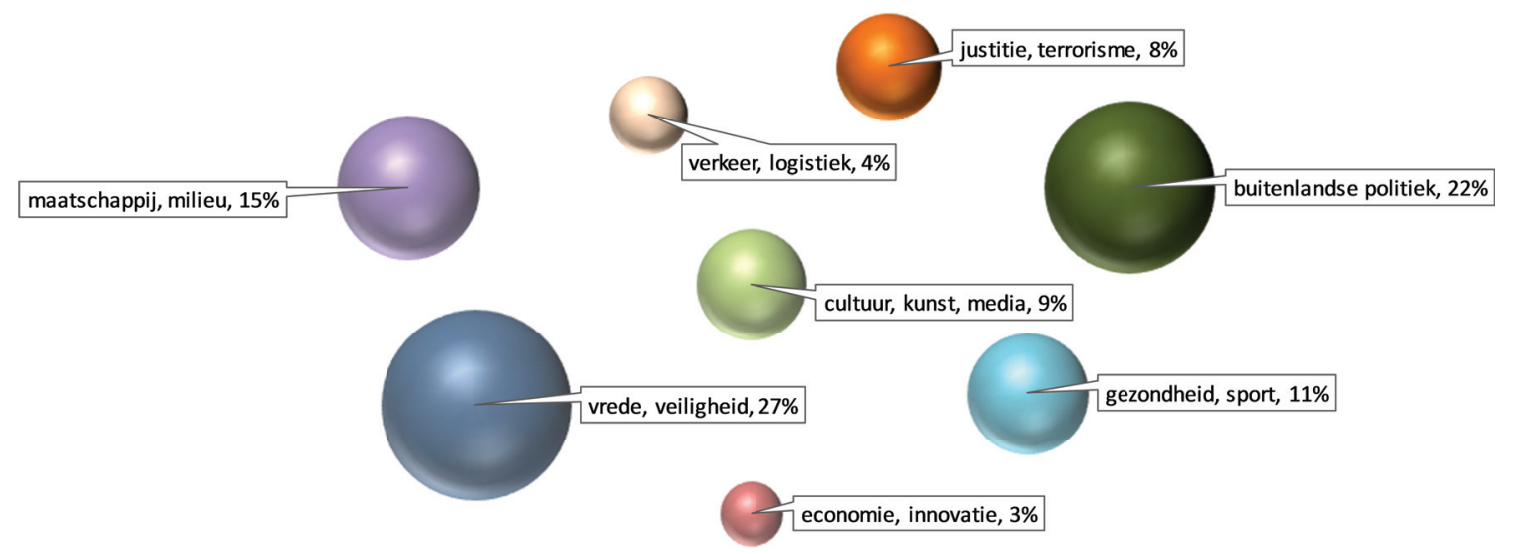

Figuur I. Algemene historische thema's in Andere tijden afleveringen met een internationale focus tussen maart 2000 en december 2016. De grafiek toont de verhouding van afleveringen per thema. ${ }^{45}$

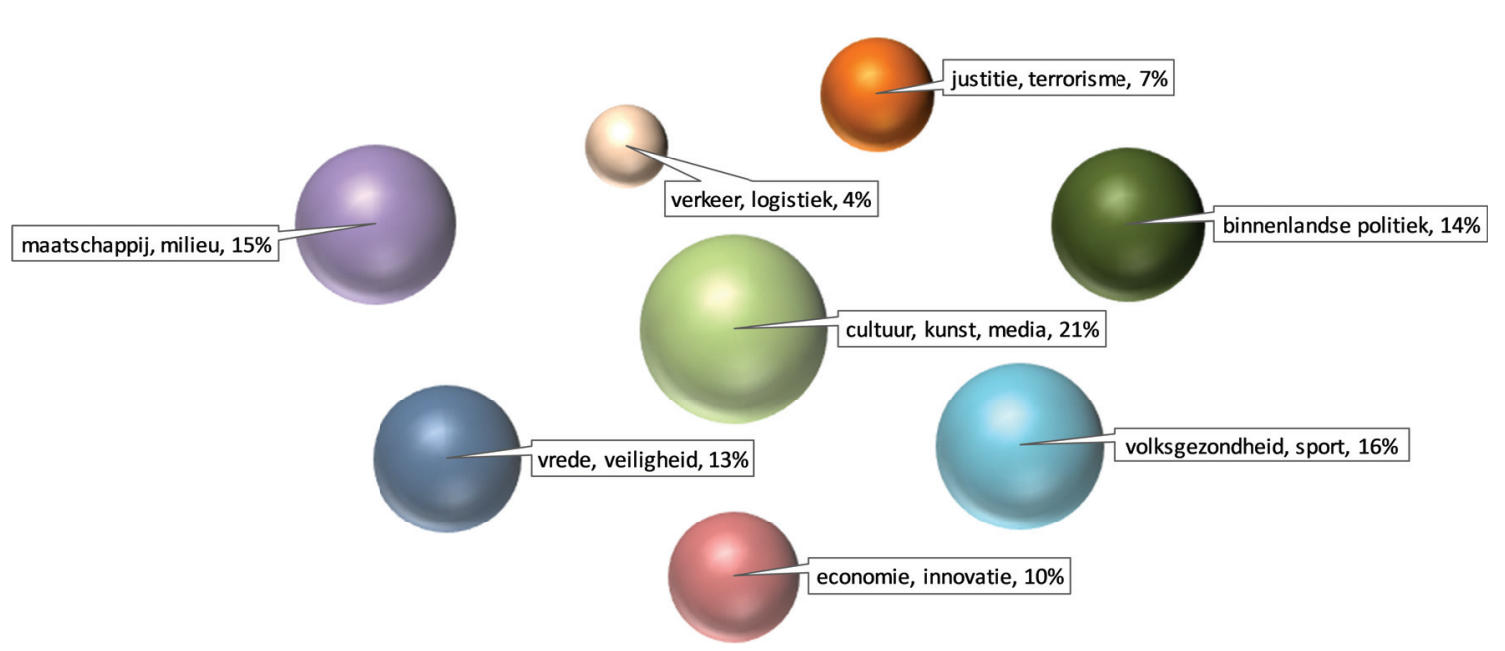

Figuur 2. Algemene historische thema's in Andere tijden afleveringen met een nationale (Nederlandse) focus tussen maart 2000 en december 2016. De grafiek toont de verhouding van afleveringen per thema. ${ }^{4}$ 


\section{Tekstuele en narratieve doelstellingen, strategieën en conventies}

Het vertellen van verhalen over het verleden is gecompliceerd. Van den Born legt uit hoe de makers van Andere tijden over de jaren steeds beter zijn geworden in hun vaardigheid om een verhaal te vertellen. Door montage en regie wordt een meer vloeiende verhaalstructuur neergezet en de makers zijn volgens haar steeds beter geworden in het overbrengen van zowel het kernpunt als de actuele relevantie van het geschiedenisverhaal. ${ }^{47}$ Andere tijden volgt grotendeels traditionele documentaire-werkwijzen door zowel het uitvoeren van feitenonderzoek als (om Bill Nichols te parafraseren) het plaatsen van fragmenten van de historische werkelijkheid in een meer retorisch of argumentatief dan een esthetisch of poëtisch frame ${ }^{48}$. Het programma volgt hierbij deels de werkwijze van de traditionele verklarende documentaire die de kijker rechtstreeks aanspreekt, een specifieke visie op de sociaal-maatschappelijke werkelijkheid voorstelt en daarbij vaak terugblikt op de geschiedenis.

\subsection{De verschillende rollen van de presentator}

Zoals onder andere Erin Bell heeft betoogd, worden kijkers vaak aangemoedigd getuigenissen door presentatoren en ooggetuigen als authentiek, gezaghebbend en uniek te zien. Dit wordt bemoeilijkt door het feit dat dergelijke getuigenissen veelal voor anderen spreken. ${ }^{49}$ Onder andere Bells werk heeft echter duidelijk gemaakt dat ideeën over hoe getuigenissen van het verleden eruit kunnen zien, verbreed zijn door de hedendaagse veranderingen in het verbeelden van het verleden op televisie. ${ }^{\circ}$ In Andere tijden biedt de presentatie en voice-over door historicus en biograaf Hans Goedkoop het 'frame' door middel van een introductie, een doorlopende verhaallijn en een conclusie. In elke aflevering fungeert Goedkoop als een betrokken commentator. Goedkoop schrijft daarbij de teksten van zijn presentatie zelf (in samenwerking met de regisseur). Om financiële en praktische redenen, die samenhangen met de duur en frequentie van opnames, presenteert Goedkoop niet vanaf locatie, maar vanuit de archieven van het

Nederlands Instituut voor Beeld en Geluid en de presentator houdt ook geen interviews met ooggetuigen..$^{\mathrm{I}}$

Vanaf de allereerste uitzending hebben de makers het belang van een 'dragende' presentator benadrukt. Contextuele historische informatie kan soms lastig te volgen zijn voor televisiekijkers. De makers stellen dat dergelijke informatie daarom moet worden verteld door iemand waar men graag naar luistert en die men als geloofwaardig beschouwt. ${ }^{52}$ In het oorspronkelijke voorstel voor Andere tijden, toen nog onder de naam OVTV, geeft Gerda Jansen Hendriks de presentator daarom de rol van 'de gepassioneerde deskundige'. ${ }^{53}$ In een latere opzet uit 1999 wordt de rol van de presentator omschreven als iemand die de kijker moet kunnen boeien en enthousiasmeren. Dat wil zeggen, net genoeg informatie geven aan de kijker om het onderwerp te kunnen begrijpen. De presentator moet de kijker motiveren om te blijven kijken, hetzij via signalen, woorden, gezichtsuitdrukking of intonatie. Eerdere programmaopzetten bevatten ook adviezen over de specifieke taak van de presentator van een geschiedenisprogramma: de presentator moet zich kunnen inleven in de tijd en de omstandigheden van het te vertellen verhaal en de televisiekijker mag niet met vragen achterblijven. ${ }^{54}$ De 'toon' wijkt daarmee in belangrijke mate af van de eerder meer ironische dan wel afstandelijke presentatie 
in Nederlandse non-fictie programma's. ${ }^{55}$ De presentator moet op kernvragen antwoord geven in zijn conclusie - hoewel Goedkoops conclusies volgens Jansen Hendriks soms als te moralistisch werden ervaren. ${ }^{56}$ Dit houdt in dat de presentatietekst relatief langer is dan bij vergelijkbare programma's en formats. ${ }^{57}$ De presentator neemt de context voor zijn rekening, waardoor de makers meer vrijheid krijgen het daadwerkelijke verhaal te vertellen. De presentator bereidt de kijker voor op de komende aflevering, en hierdoor kan de reportage daar beginnen waar het verhaal begint, zodat allerlei spanning verhogende vertelmethoden kunnen worden toegepast. ${ }^{5}$

Er worden daarbij bewuste keuzes gemaakt om de presentator op bepaalde momenten in de uitzending in beeld te brengen. Figuur 3 laat bijvoorbeeld zien hoe het scherm in de aflevering "Verboden voor Duitsers: Katendrecht in oorlogstijd" (NPS/VPRO, 29 april 2010) bestaat uit archiefmateriaal gecombineerd met beelden van Goedkoop die presenteert vanuit het Nederlands Instituut van Beeld en Geluid (met bezoekers zichtbaar in de rechterbovenhoek van het beeld).

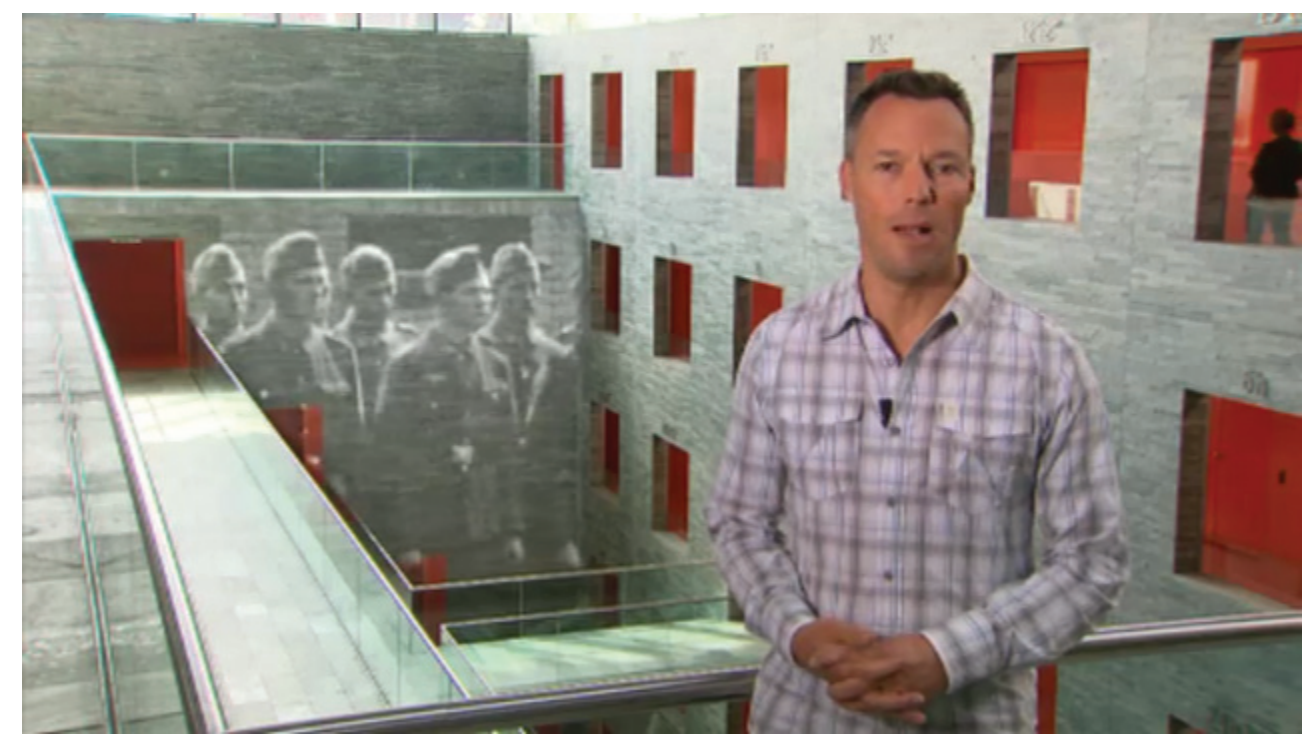

Figuur 3. Presentator Hans Goedkoop in Andere tijden aflevering "Verboden voor Duitsers: Katendrecht in oorlogstijd". Bron: Nederlands Instituut voor Beeld en Geluid. Website capture.

Goedkoops voice of authority laat ten slotte een opvallende afwezigheid van het gebruik van de tegenwoordige tijd zien, zoals bijvoorbeeld de introductietekst bij de aflevering “'De bezetting' van Loe de Jong” (NPS/VPRO, 22 oktober 2009) aangeeft, die Hans Goedkoop uitspreekt vanuit het Instituut voor Beeld en Geluid, met archiefbeelden getoond op de achtergrond:

De Tweede Wereldoorlog voor een jongere in I960. Goedenavond. Een uitzending bij de Dodenherdenking van dat jaar. De oorlog was vijftien jaar voorbij en in die jaren was er niet zoveel over gepraat. De wederopbouw ging voor, we keken vooruit, niet achteruit, en we deden niet kleinzerig. (...) Als het ging om ons beeld van de bezetting, wiens beeld moest dat zijn? Dat van de communisten die als eersten openlijk verzet hadden getoond, 
van de NSB'ers die juist mee hadden gelopen, van de joden die alles waren kwijtgeraakt, van de mensen die er juist zonder kleerscheuren waren doorgekomen? Al die beelden leefden naast elkaar, zelfs als concurrenten tegenover elkaar. Vrij pijnlijk eigenlijk. En het ontbrak aan een totaalbeeld. Dat was de situatie rond I960. Haast niet voor te stellen, maar er was gewoon geen nationaal beeld van de oorlog. Dat moest nog gemaakt. ${ }^{59}$

De gesproken woorden van de presentator zijn een belangrijke richtlijn voor kijkers om zich terug te laten voeren naar het verleden. Tegenwoordige tijd in documentaire programmering wordt volgens Steve Anderson meestal ingezet ter verduidelijking van de huidige situaties en wordt bepaald door de behoeften van het heden. ${ }^{60}$ Het gebruik van de verleden tijd door Goedkoop benadrukt juist de tegengestelde bedoelingen van Andere tijden. Het programma biedt zo een alternatief voor meer traditionelere manieren van televisie maken volgens het aloude principe van populaire geschiedenis, waarbij historische figuren en gebeurtenissen werden gebruikt om de toekomst te ontdekken. ${ }^{61}$ Ofschoon het programma hedendaagse gebeurtenissen gebruikt om het geheugen te stimuleren, treden ze in het programma niet op de voorgrond.

In Andere tijden worden het vertoonde archiefmateriaal en interviews door de manier van presenteren en door het voice-over commentaar in een imperatief kader geplaatst: de presentator duwt de televisiekijker als het ware in de richting die de regisseur voor ogen heeft. In het geval van Andere tijden wordt op deze manier teruggeblikt op een gebeurtenis uit het verleden die verband houdt met het heden.

\subsection{Het hergebruik van archiefmateriaal}

In Andere tijden worden historische gebeurtenissen uit de twintigste eeuw voornamelijk verbeeld via audiovisueel archiefmateriaal (dat geluidsmateriaal, bewegend en stilstaand beeld omvat). De beschikbaarheid van audiovisueel archiefmateriaal is een belangrijke voorwaarde voor hergebruik en bepaalt of afleveringen makkelijker of moeilijker te produceren en circuleren zijn. Soms wordt de voorkeur gegeven aan andere vormen van archiefmateriaal, zoals manuscripten of krantenartikelen. Soms moeten alle beschikbare middelen worden ingezet om een verhaal over te brengen op de televisiekijkers, met name wanneer ' clips zonder geluid, statisch of zelfs zonder 'verhaal' zijn. De regisseur gaat dan aan de slag door beelden in een bepaalde volgorde te leggen, nieuwe geluidseffecten te creëren, muziek toe te voegen en stelt een verhaallijn op door middel van voice-over commentaar en interviews. Om met Jansen Hendriks te spreken: 'Je gebruikt de hele trukendoos, die er maar zoveel mogelijk is om mensen in een bepaalde tijd te trekken. ${ }^{62}$

Wat zijn de functies van het hergebruik van archiefmateriaal in een langlopend, wekelijks geschiedenisprogramma? Allereerst kan audiovisueel archiefmateriaal dienen als 'visible evidence' - visueel bewijsmateriaal. Archiefmateriaal wordt over het algemeen ingezet als uitgangspunt voor het vertellen van een bepaalde historische gebeurtenis. Door de jaren heen hebben nieuwsuitzendingen meer en meer gediend als belangrijkste informatiebron voor het grote publiek. Hierdoor kunnen programmamakers makkelijk refereren aan informatie die in het algemeen al bekend is over een bepaald onderwerp. In de aflevering "Oorlog in Indië" 
(De oorlog, NPS, 6 december 2009) worden Indonesisch-Japanse bioscoopjournaals bijvoorbeeld als 'bewijs' getoond en zijn zo van historische betekenis. Deze bioscoopjournaals waren aanvankelijk als oorlogsbuit in Nederland aangekomen en in het kader van de bezetting slechts als Japanse propaganda beschouwd. ${ }^{6}$ Jansen Hendriks, die zich gespecialiseerd heeft in koloniale propagandafilms tijdens de Indonesische Onafhankelijkheidsoorlog, betoogt echter:

[M]aar [de bioscoopjournaals] laten juist heel goed zien hoe zeer de Japanners het lukt om de Indonesische elite voor zich te winnen en een soort nieuwe eigen staat te bouwen, weliswaar allemaal gecensureerd door Japan, enzovoort, enzovoort, maar je ziet wel: ze krijgen een eigen parlementje, en dit en dat... Toen stelde dat allemaal nog niks voor, maar het is allemaal wel ter verklaring van waarom na de oorlog die twee werelden van het Nederlandskoloniale, het Nederlands-Indië, en Indonesië zo totaal uit elkaar waren gegroeid. Daar hadden de Nederlanders echt geen idee van. En daar zijn dan die bioscoopjournaals, die laten dat heel mooi te zien. ${ }^{64}$

Archiefmateriaal kan dus letterlijk en figuurlijk dienen als bewijs dat een bepaalde gebeurtenis heeft plaatsgevonden - in hoeverre wat door een cameralens is gefilmd objectief kan helpen een historische gebeurtenis weer te geven. Archiefmateriaal vormt een belangrijke prikkel voor herinnering. Astrid Erll wijst erop hoe media kunnen fungeren als 'cue' voor herinnering en dat juist de verhalen rondom dergelijke media betekenisbepalend zijn. ${ }^{65}$ Ik betoog dat niet alleen interviews, maar ook archiefbeelden een gelijksoortige functie kunnen hebben. Audiovisuele archiefmaterialen zijn een belangrijk instrument om het verleden te verbeelden en vertegenwoordigen een representatie van of herinnering aan voorbije gebeurtenissen en personen die niet langer onder ons zijn. Langlopende, wekelijkse geschiedenisprogramma's representeren op deze wijze herinneringen aan het verleden, waaronder het eigen verleden van televisie.

Bij het samenvoegen van recentelijk gefilmde fragmenten met audiovisuele archiefbeelden worden televisiekijkers én met het heden én met het verleden geconfronteerd. Archiefbeelden bieden televisiekijkers toegang tot geschiedenis door een visuele terugblik op het verleden te bieden. Geschiedenisprogramma's laten archiefbeelden niet alleen zien als bewijs, deze beelden zijn vooral bedoeld om emoties en gevoelens met betrekking tot de gebeurtenis op te wekken als een historische ervaring. Op deze manier helpen archiefbeelden om de stemming of sfeer van het verleden op te roepen, wat vooral belangrijk kan zijn als er geen ooggetuigenverslagen beschikbaar zijn of deze een afwijkende reactie geven. Volgens Jansen Hendriks kan 'zelfs het simpelste bioscoopjournaal' zo een sensatie van het verleden teweegbrengen. ${ }^{66}$

Geluid wordt eveneens toegevoegd, want origineel commentaar uit een eerder tijdperk is volgens de makers uitermate geschikt om kijkers in een andere tijd te trekken. Dit komt overeen met het onderzoek van Leo Murray (refererend aan eerdere studies door onder andere Bill Nichols) naar de rol van geluid in documentaires. Murray stelt dat geluid - variërend van authentieke synchroonopnames tot voice-over, muziek en geluidseffecten - diverse verhalende 
en dramaturgische 'rollen' kan vervullen, zoals legitimering van de beelden, een gevoel van realisme leveren, dramatisch gewicht toevoegen, en een emotionele interpretatie bij het kijkerspubliek teweegbrengen. ${ }^{67}$ Opvallend is dat Jansen Hendriks in deze context opmerkt: '(...) waarbij ik overigens wel wil zeggen dat het beeld dan altijd wint, hè. ${ }^{68}$ Vanuit dit idee dat het beeld altijd wint - moeten, wanneer er spannende en emotionele gebeurtenissen getoond worden, deze volgens de makers daarom zorgvuldig bewerkt worden en van commentaar worden voorzien. ${ }^{69}$ Anders, zoals de makers betogen, zal wat zij willen benadrukken niet goed overkomen bij de televisiekijker.

Hierbij is uiteraard het ter beschikking hebben van archiefbeelden van groot belang. Dit hoeft echter niet te betekenen dat historische verhalen niet kunnen worden verteld wanneer bronnen beperkt beschikbaar zijn. Een goed voorbeeld is de Andere tijden-aflevering "De ondergang van de Junyo Maru” (NPS/VPRO, 25 februari 2003). In september I944 werd een Japans vrachtschip getorpedeerd vlak voor de kust van West Sumatra. Buiten medeweten van de Engelsen die dachten dat het vrachtschip was beladen met cement, vervoerde het schip in feite dwangarbeiders op weg om aan de Pakanbaroe-spoorweg op Sumatra te gaan werken. Van de 6.500 mensen aan boord kwamen er 5.500 slachtoffers om. Weinig mensen zijn zich bewust van deze tragedie. Het enige overgebleven beeld is een oude foto van het getorpedeerde schip in aanbouw.

Hoe verbeeld je zo'n historische gebeurtenis, die niet aanwezig is in het collectieve geheugen, op televisie? Ofschoon het niet de hoogste prioriteit had, heeft de redactie van Andere tijden lang onderzoek gedaan naar het oorspronkelijke verhaal. Hans Goedkoop kondigt uiteindelijk het verhaal aan met de volgende openingszin: 'Eens in de zoveel tijd brengen we $u$ een verhaal, niet omdat er een directe oorzaak voor is, maar gewoon omdat het een verhaal is dat ooit verteld moet worden. Een verhaal waarvan je niet kunt voorstellen dat niet iedereen het al weet. ${ }^{70}$ De introductie door Goedkoop geeft het onbekende item wat de makers 'kijkerswaarde' noemen. Een belangrijk motief voor Van Liempt was te ontdekken hoe het de kapitein was vergaan toen hij uiteindelijk vernam dat hij geen vrachtschip had getorpedeerd, maar in feite duizenden onschuldige mensen had gedood. Alhoewel de kapitein, S.L.C Maydon, inmiddels was overleden, kwam men op het spoor van zijn zoon Robert Maydon, die ook bij de marine had gediend en in Afrika woonde. Op een zeker moment gaat hij tijdens de kerstvakantie op bezoek in Engeland en is bereid het verhaal van zijn vader te vertellen. ${ }^{7 \mathrm{I}}$ Robert Maydon vertelt hoe zijn vader per post een tape uit Amerika had ontvangen waarop overlevenden hun verhaal vertelden en hoe de kapitein voor de eerste keer vernam dat hij de dood van meer dan 5.500 mensen had veroorzaakt. Kort nadat hij de band had ontvangen, kwam zijn vader in het reine met wat er gebeurd was: 'Het was iets dat was gebeurd in zijn leven en het was geschiedenis'. ${ }^{2}$ Aanvullende tekst uit het interview met Robert Maydon op de Andere tijden website biedt nadere duiding en contextinformatie: 'Mijn vader was van een andere generatie. Over de oorlog sprak je niet. En voor hem gold dat het aantal slachtoffers dat hij had gemaakt nu opeens een stuk hoger was geworden. Maar, zo zei hij, daar kan ik nu toch niets meer aan veranderen. ${ }^{73}$ Dit verhaal is een voorbeeld van een gebeurtenis waarvan de makers vonden dat 'het moest worden verteld' en is geproduceerd zonder een prominente koppeling met de actualiteit of, buiten de genoemde foto, met archiefmateriaal. 
Zoals de aflevering "De ondergang van de Junyo Maru” een voorbeeld is van een verhaal met bijna geen archiefmateriaal, is de eerder genoemde aflevering "Een Indische familie" een voorbeeld van een verhaal waarbij alleen maar archiefbeelden worden gebruikt: 8mm amateurfilms die net voor aanvang van de oorlog in het vroegere Nederlands-Indië werden gemaakt. Volgens de makers moest ook dit verhaal gewoonweg verteld worden, ook zonder directe aanleiding uit de actualiteit. Het jonge echtpaar, Hans en Noes Fischer, was in I937 naar Nederlands-Indië vertrokken en maakte met een $8 \mathrm{~mm}$ camera amateurfilms om hun familie thuis in Nederland te laten zien hoe het leven in het buitenland was. Tragisch genoeg overleefde de familie de oorlog niet en deze amateurfilms zijn alles wat ze hebben nagelaten. In eerste instantie heeft regisseur Jansen Hendriks geprobeerd om mensen te vinden die de familie hadden gekend voor een ooggetuigenverslag, maar dit leidde tot niets. Het gebrek aan voldoende 'herinneringen' voor het televisieprogramma, bracht haar op het idee om in de aflevering uitsluitend gebruik te maken van het beschikbare archiefmateriaal: het eigen materiaal van de familie in de context van die periode. Dit zou de standaardaanpak worden voor de populaire Andere tijden special die sinds 2004 jaarlijks wordt uitgezonden, meestal zonder interviews of verklarend commentaar maar uitsluitend bestaand uit een bijna urenlange screening van archiefbeelden.

Naast toegang en beschikbaarheid zijn er nog verschillende factoren die een factor vormen bij de selectie van archiefbeelden, aldus beeldresearcher en redacteur Lizzy van Winsen. ${ }^{74}$ De makers beslissen meestal over de inhoud van een aflevering vóór de selectie van audiovisueel materiaal. Het beschikbare budget is daarbij in grote mate leidend. Als het materiaal van groot belang is, zullen de makers er wel alles aan doen om dit te kunnen gebruiken (als het materiaal heel duur is door bijvoorbeeld op andere posten proberen te bezuinigen) - maar minder budget betekent over het algemeen dat een groter gedeelte van het te vertonen materiaal afkomstig zal zijn uit de archieven van het Nederlands Instituut voor Beeld en Geluid. Digitalisering van audiovisueel materiaal is bovendien een belangrijke factor, naast de kwaliteit van het audiovisuele archiefmateriaal zelf en natuurlijk, de beschikbare tijd voor de researchers om hun onderzoek uit te kunnen voeren. Andere tijden heeft ongeveer zes weken nodig om een aflevering te produceren, maar afleveringen kunnen ook in een korter tijdsbestek worden geproduceerd vanwege de actualiteit.

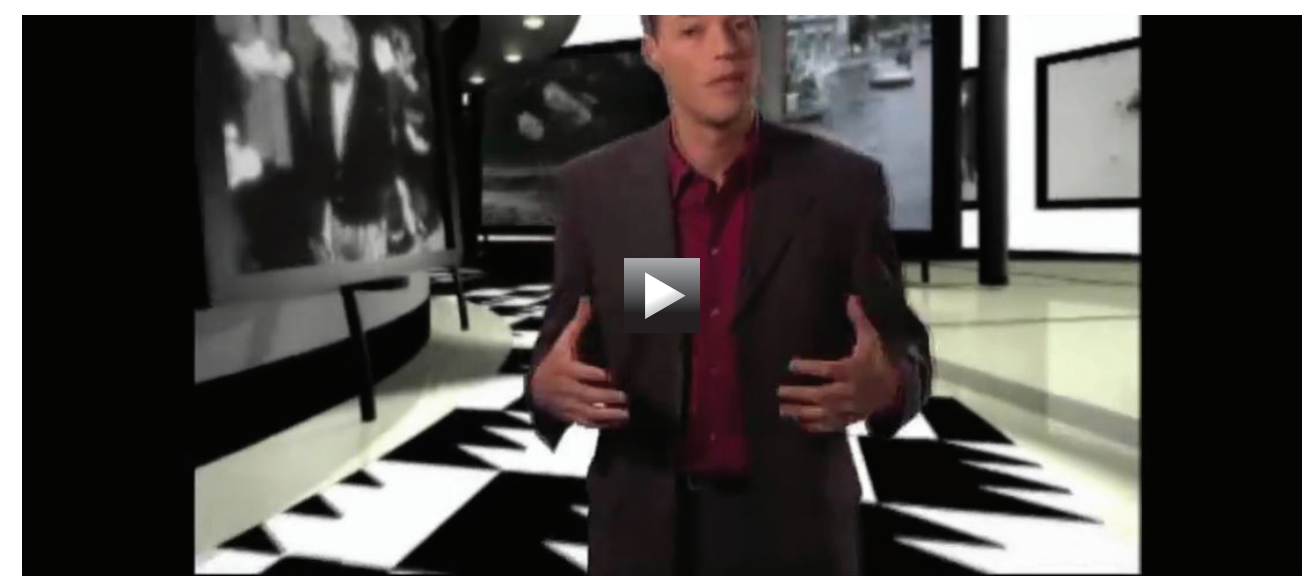

Andere tijden aflevering "De ondergang van de Junyo Maru” (NPS/VPRO, 25 februari 2003). 


\subsection{Ooggetuigenverslagen en herinneringspraktijken}

In documentaires en televisieprogramma's over het verleden worden historische gebeurtenissen vaak verteld in interviews met mensen die deze gebeurtenissen zelf hebben ervaren. Net als de toegankelijkheid van archiefbeelden is de beschikbaarheid - en bereidwilligheid - van ooggetuigen hier een belangrijke voorwaarde voor de productie van een verhaal. Inherent aan dit soort getuigenissen is het feit dat de talking heads tot op zekere hoogte zijn geïnstrueerd het is dan ook een ingewikkelde praktijk die veel vragen oproept over authenticiteit. ${ }^{75}$ Voordat de regisseur begint met het interviewen van ooggetuigen, wordt samen met de onderzoekers een 'shooting script' gemaakt. Dit zorgt ervoor dat het interviewproces relatief gestructureerd verloopt. Dit is vooral belangrijk, wanneer het doel van het interview is om herinneringen op te halen. Dit kan uren in beslag nemen. De aanpak van de interviewer en de daaropvolgende interviewvragen zijn gebaseerd op de beschikbaarheid van archiefmateriaal en het uitgevoerde (beeld-)onderzoek.

De analyse van verschillende tekstuele voorbeelden geeft de strategieën van de makers weer in de opbouw van televisiegetuigenissen. De Andere tijden-aflevering "Oorlog in blik" (NPS/VPRO, I6 september 20I0) is daarvan een voorbeeld. Deze aflevering was geproduceerd in afwachting van de Oorlog in blik-website, een online site die toegang geeft tot de audiovisuele geschiedenis van Nederland in 1930-I955 door amateur- en professionele filmmakers. In "Oorlog in blik" is een interview met Sonja de Marcas-Ossedrijver te zien over de amateurfilms ('Berleo producties') die haar vader Bernard en oom Leo Ossedrijver maakten als Joodse familie in de Plantagebuurt in Amsterdam tijdens de Tweede Wereldoorlog. In deze aflevering blikt De Marcas-Ossedrijver terug op de amateuropnames, en geeft voice-over commentaar aan de hand van de beelden op het scherm. Kijkend naar de amateurfilms gemaakt door haar vader en zijn broer (in het betreffende geval over het luchtafweersysteem) roept haar manier van vertellen in de derde persoon in eerste instantie onpersoonlijke dialogen op: '23 juni i940. Berleo film. Een tekeningetje van pap. De operateur die het opnam was blij dat hij "besjolem" beneden kwam. Papa met een sigaret in z'n mond. En de man erachter natuurlijk ook.' De Marcas-Ossedrijver neemt vervolgens afstand van haar vertelling van de afgebeelde gebeurtenissen, en neemt de rol aan van sociale commentator: 'Roken tot je er bij neer valt. ${ }^{76}$ De Marcas-Ossedrijver neemt echter de rol van hoofdpersoon aan in haar beschrijving van het specifieke geval van de thuiskomst van oom Leo na de oorlog, in levendige details in haar vertelling in de eerste persoon ('wat ik me ook herinner...'):

Wat ik mij ook herinner... Maar dat was dan weer na de oorlog, toen oom Leo thuis kwam. Oom Leo is dus op de een of andere manier gered door de Russen, die dat kamp hebben ontzet. En is toen gaan zwerven door Rusland, toen werd aan de deur gebeld en toen hoorden we beneden roepen: 'Bernard!' En Bernard, die hoorde de stem van mijn oom. Oom Leo werd vaak door mijn vader Illy genoemd. En vraag me niet waarom, Illy. Dus hij zei: 'Illy!' Hij racete, moet je voorstellen, die hoge trappen, hij racete die trappen af. Dat was echt een, als ik daaraan denk... [wordt zichtbaar emotioneel] moet ik heel even een traan...77 
Aan het einde van het verhaal gaat de gesproken tekst van De Marcas-Ossedrijver weer over in een herhalend discours, de meest voorkomende vertelstijl bij het ophalen van herinneringen: ${ }^{78}$ 'Hij [Oom Leo] had een schermpje. Dat werd in de huiskamer opgezet en dan keken we daarnaar. En dan zagen we weer al die familieleden die we niet meer hadden' ${ }^{79}$

De vertelling door De Marcas-Ossedrijver roept diverse herinneringen op, en toont de kracht die film en televisie uit het verleden oproepen in het heden. Dit wordt niet alleen geïllustreerd door de verschillende discursieve registers van De Marcas-Ossedrijvers 'televisieautobiografie', maar ook door de films die hergebruikt worden in het getoonde verhaal: '(...) en dan zagen we weer al die familieleden die we niet meer hadden.'

Soms wordt deze strategie gecombineerd met het bezoeken van historische locaties, en soms met specifieke geluiden die op deze locaties aanwezig zijn. In de Andere tijden-aflevering "De ontvoering van Herrema" (NPS/VPRO, 2I oktober 20IO) bijvoorbeeld bezoekt de Nederlandse zakenman Tiede Herrema voor de tweede keer de plaats waar hij in I975 door twee ex-leden van de IRA werd ontvoerd. De aflevering roept een ander soort autobiografisch discours op. Herrema bezoekt opnieuw een belangrijke herinneringsplek: het huis waar twee ex-IRA-leden hem meer dan zeven weken gevangen hielden. Staande voor dit huis laat een passerende trein hem schrikken. Hij legt uit dat de passerende trein hem in I975 ook liet schrikken:

Een trein passeert. Herrema is zichtbaar geschrokken, maar glimlacht dan: 'Maar dit is [wijst naar de spoorweg], dit is zeer schokkend voor mij. Die trein... [Geluid van de trein vervaagt.] Het jaagt me schrik aan.'

Interviewer [buiten beeld]: 'Waarom?'

Herrema: 'Omdat het me destijds ook schrik aanjoeg. [Grijnst.] Sorry'. ${ }^{80}$

Het verhaal van Herrema wordt direct gevolgd door archiefbeelden van de dezelfde spoorlijn en het geluid van een passerende trein uit 1975 - die de kijker contextuele informatie geven over Herrema's herinneringen. Dergelijke voorstellingen van het geheugen op het scherm verbeelden het gevoel van hoe het is om te herinneren.

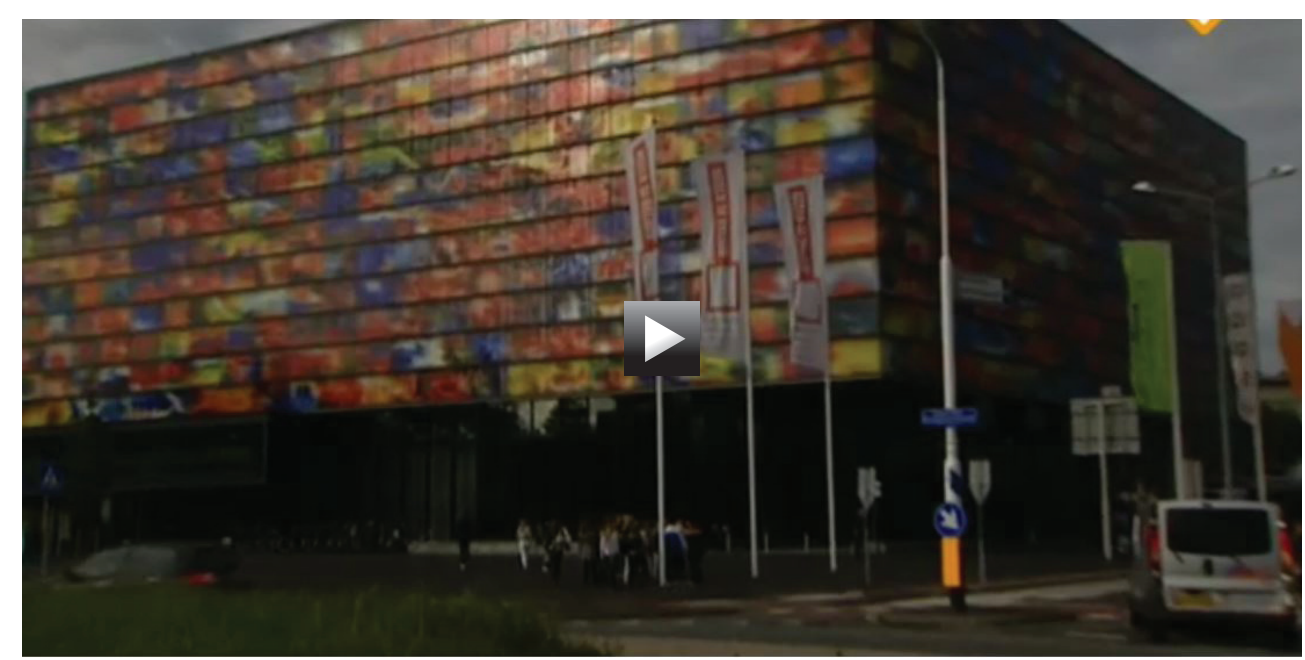

Andere tijden aflevering "Oorlog in blik" (NPS/VPRO, 16 september 2010). 
Annette Kuhns studie biedt een uitgangspunt om dergelijke televisiegetuigenissen als 'herinneringsverhalen' te begrijpen waarin het verleden wordt geproduceerd in de activiteit van het herinneren. Zulke representaties vertegenwoordigen echter niet direct het verleden 'zoals het was' ${ }^{8 \mathrm{I}}$ Zoals Kuhns onderzoek duidelijk maakt, is het minder gewoon dat hierbij anekdotische of autobiografische discoursen voorkomen, vanwege het zeer levendige karakter van dergelijke uitingen. Andere tijden laat de kracht zien van archiefbeelden en plaatsen van herinnering om het autobiografisch geheugen wel degelijk op te roepen en te laten ontstaan door middel van televisiepraktijken - en zo wordt onze blik verruimd van hoe een getuigenis van historische gebeurtenissen eruit zou kunnen zien.

\subsection{Drama en re-enactment}

Re-enactment van scènes is door de makers 'verboden' ter bescherming van de geloofwaardigheid van het programma en het onderzoek door de researchers. De programmamakers zijn zich sterk bewust dat televisiekijkers de neiging hebben te veronderstellen, dat als één aspect van het programma 'niet waar' is, dat de rest ook wel 'niet waar' zal zijn. Alhoewel de echte waarheid nooit zal worden bereikt, proberen de makers zo dichtbij mogelijk te komen in hun zoektocht naar authenticiteit:

Dat is de centrale gedachte. Dat op het moment dat je die lijn loslaat van de authenticiteit, dat je je eigen geloofwaardigheid te grabbel gooit, want daar is naar mijn idee de mensen in het algemeen, en de Nederlander in het bijzonder, bijzonder wantrouwig over. ${ }^{82}$

De interviews met de makers maken duidelijk dat zij zichzelf beschouwen als 'de laatste der Mohikanen' in hun strikte onverdraagzaamheid van nagespeelde scènes. Van Liempt betoogt dat het nationale, calvinistische karakter van de Nederlanders altijd zal streven naar betrouwbaarheid en een programma onbetrouwbaar achten wanneer bepaalde elementen nagespeeld zijn. Volgens de makers gaat het hier niet om de jonge televisiekijkers - een vergelijking wordt hier gemaakt met de nasynchronisatie in het Nederlands van televisieprogramma's in een vreemde taal: vanaf een meer volwassen leeftijd is dit niet aanvaardbaar meer voor het Nederlandse publiek. ${ }^{83}$

\section{Cultuurhistorische doelstellingen, strategieën en conventies: specifieke vraagstukken bij geschiedenis verbeelden op televisie}

\subsection{De rol van historici en andere experts}

Alle geïnterviewde programmamakers erkennen het belang en de noodzaak experts te raadplegen op het gebied van de historische gebeurtenissen die in een specifieke aflevering worden aangehaald. Zij kunnen belangrijke standpunten aandragen, die vervolgens door de programmamaker kunnen worden overgenomen in het gebruikte commentaar, de structuur van de aflevering, enzovoorts. Op deze manier kunnen historici de programmamakers helpen bij een bepaalde programma-aanpak. De maker verkrijgt niet alleen stof tot nadenken en 
belangrijke kennis over een bepaald onderwerp, maar ook een manier van aanpak met betrekking tot een onderwerp waar de programmamaker mogelijk zelf niet veel ervaring mee heeft.

Historici en andere deskundigen of professionals worden geraadpleegd in het productieproces en functioneren als een bron van informatie. Zulke experts worden echter bij voorkeur niet gebruikt als talking heads, omdat zij vaak geen persoonlijke link hebben met de bestudeerde historische gebeurtenissen - zij zijn (uitzonderingen daargelaten) ook geen ooggetuige of ervaringsdeskundige. Hoewel Andere tijden sinds het eerste seizoen verhalen uit zowel de eerste en de tweede helft van de twintigste eeuw heeft uitgezonden, belemmert dit basisprincipe de productie van verhalen uit de eerste helft van de twintigste eeuw. Ooggetuigenverslagen uit de eerste helft van de twintigste eeuw zijn immers minder gemakkelijk te achterhalen. Er zijn echter verschillende succesvolle voorbeelden, zoals de aflevering "Misdaad in Oss" (NTR/VPRO, I7 september 20II) over de beruchte bende van Oss in de jaren I920 en I930. Deze aflevering combineert oral history via ooggetuigenverslagen met deskundig commentaar door een historicus.

\subsection{Authenticiteit}

Authenticiteit is een verwarrende factor, omdat (zoals al eerder gesteld is) het verleden niet direct gerepresenteerd kan worden 'zoals het was'. Problemen met herinneringen door ooggetuigen, vervormingen, onjuiste voorstellingen van zaken: de makers moeten hier altijd rekening mee houden. Uit mijn gesprekken met de makers kwam het streven naar authenticiteit vooral naar voren als het kunnen overbrengen van een plausibel, geloofwaardig verhaal. De programmamakers selecteren bij voorkeur vertellers die niet alleen een 'goed' geheugen hebben, maar die ook een 'autoriteit' zijn betreffende het gespreksonderwerp. Dit type getuigenissen is daarom voornamelijk gebaseerd op zeer individuele getuigenverklaringen. Om authenticiteit op een hoger niveau dan deze persoonlijke ervaringen te bewerkstelligen, zoals op het niveau van militaire leiders en leidinggevenden, moeten de programmamakers zich dikwijls van andere praktijken bedienen. Eén manier is het gebruik van egodocumenten zoals dagboekfragmenten en brieven, die voor een verhoogd gevoel van authenticiteit kunnen zorgen.

Alle programmamakers erkennen het belang gebeurtenissen zo historisch correct mogelijk weer te geven. Hein Hoffmann, regisseur van Andere tijden en De slavernij, herinnert zich zijn sollicitatiegesprek met Van Liempt:

Toen ik ging solliciteren vroeg Ad: 'Vind je het belangrijk, dat vliegtuig?' Ja (...), als Rotterdam gebombardeerd wordt door type A moet je niet type D laten zien. Zo ben ik wel. Enne (...), als je het hebt over een Opel, moet je geen Ford laten zien. Als je het hebt over een auto, maakt het niet uit, maar als je het hebt over een specifieke auto en type, moet je het wel zoveel mogelijk proberen te doen. Als je het hebt over treinen uit de jaren '40 dan moet je geen trein uit de jaren ' 50 laten zien. Er is altijd wel iemand, die het weet. "There is always a big nose, who knows!” ${ }^{4}$ 
Dienovereenkomstig moet volgens de makers de essentie van het historische verhaal op een zo waarheidsgetrouwe manier worden weergegeven. De insteek van de "Andere tijden-school" om de geschiedenis zo nauwkeurig mogelijk te benaderen kent een zeker spectrum en kan worden onderverdeeld langs de lijnen van de 'rekkelijken' en de 'preciezen'. Hoffmann:

Ja, het ligt eraan wat voor onderwerp je aanpakt. Als het een oral history is, dan maakt het me niet uit wat ze zeggen. Hoe zij het beleefd hebben, dat vind ik op zich in veel gevallen het belangrijkste. (...) Bij ons heb je de rekkelijken en de preciezen. Nou (...), ik ben de rekkelijke, kan ik je wel zeggen. Bij mij gaat het erom, de essentie moet wel weer waar zijn, maar of ze nou met de linkerhand geschoten hebben of met de rechter, dat maakt me niet zoveel uit. En (...), ze moeten geen aperte onzin uitkramen, het moet(... ja..., nee..., dat kan niet..., maar het moet redelijk kloppen. Ik heb het gevoel, dat sommige dingen nooit helemaal kloppen terwijl je het archiefmateriaal hebt om het te bewijzen, maar... nee... ${ }^{85}$

De 'precieze' Jansen Hendriks, zelf historicus, betoogt over het combineren van de verantwoordelijkheid als historicus met de verantwoordelijkheden als maker: 'Ik word betaald als televisiemaker, hoor, niet als historicus. Dat is heel flauw, maar het is wel zo, en dat heeft dus voorrang. ${ }^{86}$. Het onderscheid tussen rekkelijk en precies zit ' $m$ dus niet zozeer in de vraag of verantwoordelijkheden als televisiemaker voorrang krijgen.

\subsection{Het probleem van oral history}

Hoe onbetrouwbaar het geheugen ook kan zijn, een grote beschikbaarheid van ooggetuigenverklaringen is erg belangrijk volgens de makers van Andere tijden. ${ }^{87}$ Het kan een doorslaggevende factor zijn om niet door te gaan met een bepaald historisch verhaal wanneer er niet genoeg of geen ooggetuigenverslagen beschikbaar zijn. In die gevallen dat er geen ooggetuigen meer zijn, moeten er zeer goede extra redenen zijn om een uitzondering te maken. Geschiedenis is een proces van bewerken, en de mensen die geselecteerd worden om hun verhaal op het scherm te delen moeten goede vertellers zijn. De programmamakers zijn zich zeer bewust van de mogelijke onbetrouwbaarheid van oral history: als mensen onnauwkeurigheden vertellen wordt dit bewust geschrapt tijdens het montageproces of de televisiekijker wordt erop gewezen.

In sommige gevallen zijn 'leugens', fouten of radicaal verschillende meningen ook opzettelijk opgenomen in het programma om een specifiek punt te maken. In de Andere tijdenaflevering "Het optimisme van generaal Spoor" (NTR/VPRO, I4 mei 20II) bijvoorbeeld wordt ingegaan op de gebeurtenissen rond het leven en de dood van de jonge leger opperbevelhebber Simon Spoor in I949. Het idee voor de uitzending vloeit voort uit nieuwe feiten in de in $201 \mathrm{I}$ gepubliceerde biografie Generaal Spoor, Triomf en tragiek van een legercommandant door Jaap de Moor. ${ }^{88}$ Het interview met de weduwe van Spoor bespreekt de excessen waar Spoor als opperbevelhebber in Nederlands-Indië mee te maken kreeg. Biograaf De Moor bevestigt dat Spoor alle verslagen las maar om een aantal redenen werd er geen strafvervolging opgelegd. Echter, in het televisie-interview verklaart de weduwe van Spoor, Mans Spoor-Dijkema, letterlijk: 'Elke week waren er zulke stapels van vonnissen van de rechtbank, die hij allemaal 
door moest lezen. ${ }^{89}$ (mijn cursivering; BH) Spoor las ongetwijfeld veel verslagen over verschillende calamiteiten, waarop hij uiteindelijk in samenwerking met de procureur-generaal besloot geen actie te ondernemen. Jansen Hendriks verwacht dat deze verslagen in het geheugen van Spoor-Dijkema 'vonnissen' zijn geworden:

Ik denk, dat dus... in haar geheugen zijn het vonnissen geworden. (...) Ik heb het in dit geval laten zitten, omdat het zo duidelijk haar herinnering is en... nou ja... versus de biograaf die duidelijk maakt hoe het dan zit. En ik vind het ook wel legitiem, want als weduwe, ja natuurlijk... je gaat... dat is... dat vind ik ook niet erg. Dat vind ik eigenlijk zelfs wel mooi (...) het zijn wel van subtiliteiten in zo'n programma die over het algemeen ook heel snel weg zijn, want het komt voorbij en het is weg. ${ }^{90}$

Dit is echter geen reden voor de makers om het verhaal niet in de uitzending op te nemen.

Bij sommige onderwerpen kan de vervorming of onjuiste voorstelling van zaken zo sterk zijn, dat de makers helemaal geen interviews opnemen in een aflevering. In de Andere tijden "Special: door soldatenogen" (NPS/VPRO, 27 december 2009) besloot de regisseur bijvoorbeeld resoluut alleen dagboekfragmenten en brieven op te nemen. Dit was een bewuste keuze, gebaseerd op het feit dat, in de eerste plaats, de historische gebeurtenissen van de oorlog in Nederlands-Indië meer dan zestig jaar geleden hadden plaatsgevonden, maar in de tweede plaats, dat veel mannen die teruggekeerden met de nek werden aangekeken en bestempeld werden als 'koloniaal' en 'niet goed'. Veel van die mannen waren daarom niet bereid deze gebeurtenissen opnieuw op te rakelen. Daarom koos regisseur Jansen Hendriks ervoor mogelijke problemen met ooggetuigenverslagen te omzeilen en een 'meer authentieke' beeld te laten zien:

Ik ben echt geen geheugenexpert, maar ik merk gewoon met oude mensen, dat zij vaak een soort vast verhaal in hun hoofd hebben, en dat vertellen ze, en zodra je daarbuiten gaat

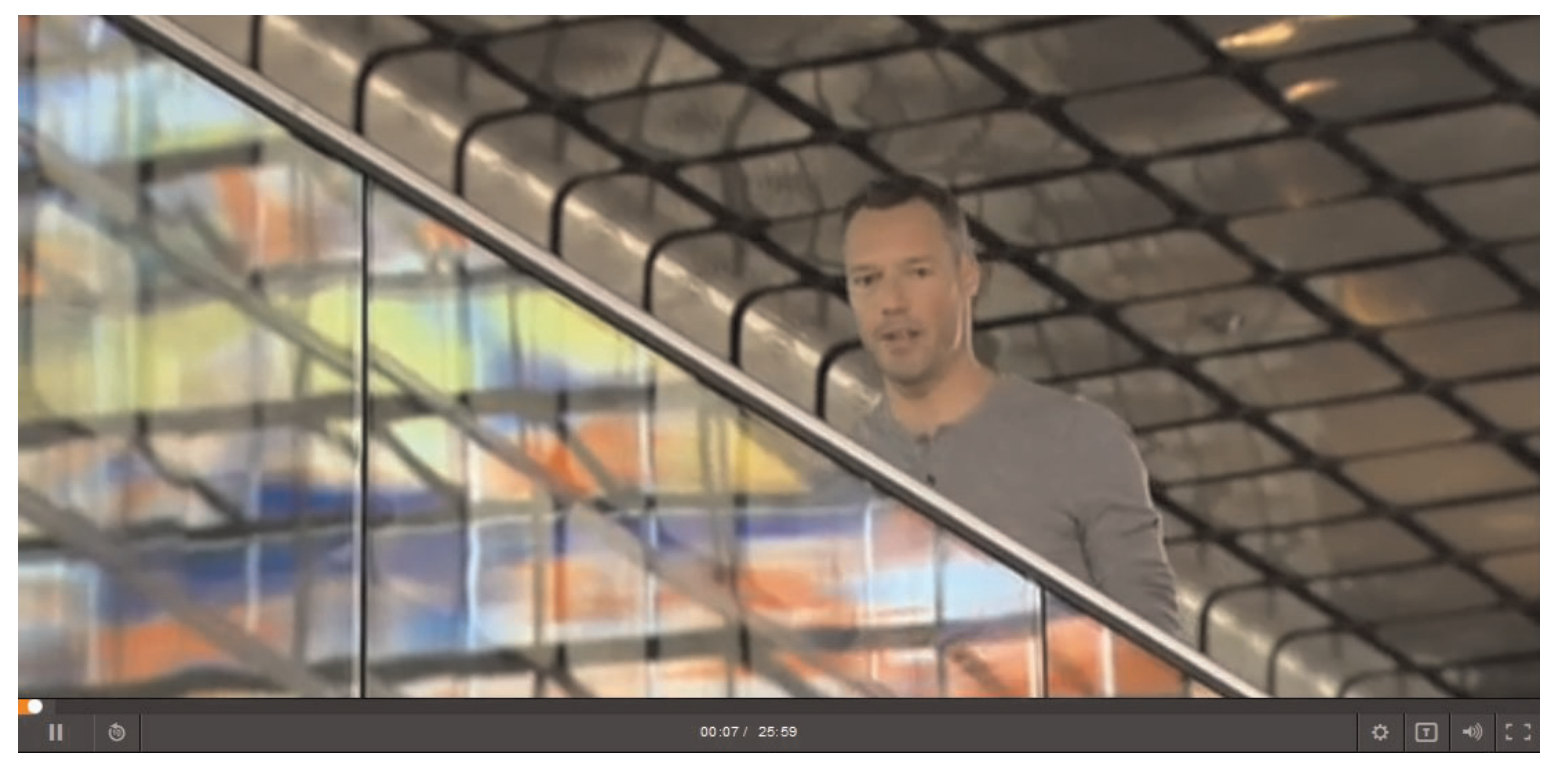

Andere tijden aflevering "Het optimisme van generaal Spoor" (NTR/VPRO, 14 mei 2011). 
vragen dan weten ze het niet meer of ze denken... weet je... oprecht weten ze het niet meer, want het is zover in hun geheugen weggestopt. ${ }^{\text {I }}$

De televisiemakers denken daarom na in hoeverre ooggetuigenverslagen worden beïnvloed door het verstrijken van de tijd en tussenliggende gebeurtenissen. Het gebruik van egodocumenten kan een oplossing bieden voor het 'meer authentiek' vertegenwoordigen van een historische periode, vaak in combinatie met (amateur-)archiefbeelden.

\subsection{Een geschiedenis voor wie? De doelgroep aanspreken}

Onderzoekers zoals Brian Winston en Derek Paget betogen dat de hierboven besproken claim op 'de waarheid', die zo'n noodzakelijk onderdeel vormt van documentaires en historische programma's, voornamelijk van de kijkers afkomt: zij hebben er bij aanvang al vertrouwen in en dit is bepaald door de karakteristieke kenmerken van het genre. ${ }^{92}$ Daarom ter afsluiting de volgende vraag: wat voor doelgroep hebben de programmamakers voor ogen bij het vertellen van de geselecteerde verhalen over het verleden?

De bedenkers van Andere tijden omschrijven de doelgroep voor hun geschiedenisprogramma als zeer ruim. Aan de ene kant refereren de makers aan zichzelf als 'ouderwetse' programmamakers die niet in termen van doelgroepen denken. ${ }^{93}$ Aan de andere kant streven ze er naar een zo breed mogelijk publiek te bereiken. Van Liempt omschrijft de doelgroep van Andere tijden als volgt:

Dat is een hele ruime doelgroep. Ik heb ' $m$ altijd geformuleerd voor mijzelf als de groep mensen, die 'wil weten wat er in de wereld aan de hand is'. Het is in feite de groep die televisie voor een belangrijk deel als informatief medium gebruikt. Maar daarmee sluit ik niemand per definitie uit; maar wij bereiken natuurlijk niet de couch potato [tv-junkie], die acht uur per dag naar amusement kijkt. Zouden we wel willen, maar die bereiken we niet. Maar als je ' $m$ zo definieert kom je in Nederland op een groep van wel vier miljoen mensen. ${ }^{94}$ (mijn cursivering; BH)

Tegelijkertijd zijn deze groep mensen ook heel druk met 'andere dingen'. Dit betekent dat volgens de makers deze groep niet bestaat uit mensen die het meest televisiekijken. De makers realiseren zich dat het hier actieve mensen betreft en dus, selectieve kijkers. Van Liempts uitgangspunt is daarbij altijd geweest dat programmamakers zich niet mogen vervreemden van hun publiek, door van een zeker basisniveau of kennis uit te gaan, laat staan in een vreemde taal uit te zenden zonder ondertiteling. De programmamakers zijn strikt in de opvatting alles te vertalen wat niet in het Nederlands gesproken wordt, om geen kijkers uit te sluiten of zelfs te beledigen: 'Als je één minuut Engels onvertaald uitzendt, dan stuur je in Nederland echt heel veel mensen de kamer uit en dat vind ik echt.' 95 Dit houdt ook in dat het taalgebruik in het programma geen zeer moeilijke woorden of zinnen mag bevatten. Een succesvolle uitvoering volgens de makers hangt af van zowel professionele vaardigheden als de kunst van helder schrijven - de laatste is voor de makers het belangrijkste uitgangspunt voor alle programma's. 
Aangezien televisie maken een in hoge mate gestandaardiseerde praktijk is, zal deze opvatting vandaag de dag en ook de komende tijd zeker nog de regel zijn voor Andere tijden. Het zal echter interessant zijn om te zien welke rol nieuwe online vertelvormen, nieuwe manieren van 'storytelling' en de verdergaande fragmentatie van het publiek in de toekomst mogelijk kunnen gaan spelen.

\section{De poëtica van het verbeelden van geschiedenis op broadcast televisie}

Zoals de casus van Andere tijden laat zien, is de interactie en onderhandeling met geschiedenis door televisiemakers een belangrijke praktijk om het verleden en herinneringen te zoeken, te behouden en te verbeelden. De analyse toont de mogelijkheden voor een grotere samenhang van poëtica - in het kort: hoe werkt het? - in het geval van geschiedenis op broadcast televisie via een wekelijkse serie, en biedt inzicht in de discussies en diverse processen van betekenisconstructie die hierbij plaatsvinden. Daarbij zijn in het bijzonder de meer impliciete praktijken van selectie en interpretatie door televisiemakers als curatoren van het verleden expliciet gemaakt, op cultuurhistorisch, institutioneel en tekstueel niveau. Een langlopend programma makt bovendien gebruik van een nog grotere intertekstualiteit en cohesie van historische programma-inhoud. ${ }^{9}$ Tegelijkertijd staat een algemeen herkenbare poëtica nog steeds onderlinge verschillen toe tussen makers.

De analyse laat de specifieke manieren zien waarop televisiemakers de aandacht van de kijker trekken en informatie overbrengen door middel van verschillende representatiestrategieën. De methodologie van tekstanalyse in combinatie met een aanpak uit het vakgebied van de productiestudies geeft inzicht in het maakproces met de bijhorende conventies, strategieën en doelstellingen, de gevolgen van deze keuzes, en uiteindelijk de onderlinge samenhang tussen inhoud en productie van geschiedenis op broadcast televisie (als processen van double mediation). Op televisie uitgezonden getuigenissen laten daarbij de kracht van archiefbeelden en plaatsen van herinnering zien voor het construeren van herinnering via televisiepraktijken. Dergelijke praktijken verbreden ons idee over hoe een getuigenis over historische gebeurtenissen eruit kan zien. Geschiedenistelevisie toont daarbij ook herinneringsverhalen over televisie zelf - geschiedenistelevisie hergebruikt én contextualiseert het eigen verleden van televisie op deze wijze. Toegang tot en selectie van archiefmateriaal zijn van doorslaggevend belang en uitdagingen voor de online circulatie van dit soort programma's in de toekomst zullen daarom gerelateerd zijn aan de vele archiefbeelden die hergebruikt worden en bijkomende rechtenkwesties. ${ }^{97}$

De poëtica van Andere tijden laat zien dat geschiedenis niet alleen altijd een proces van bewerking is, maar dat de kunst van een geschiedenisprogramma op broadcast televisie maken ligt in het vermogen om wat er in het verleden gebeurd is door middel van diverse representatiestrategieën begrijpelijk te maken voor een breed publiek. Andere tijden is een begrip geworden op de Nederlandse televisie, vooral door het verwerven van een reputatie in het hergebruik van archiefbeelden. Het produceren van de serie en het bijbehorende (beeld-) onderzoek duurt relatief langer dan bij andere wekelijkse televisieseries. Dit komt vooral door de kritische houding van de makers ten opzichte van het gebruik van de bronnen. De geloofwaardigheid van het programma (en in die zin ook de kosten van het uitgevoerde 
(beeld-)onderzoek) worden gewaarborgd door onder meer de weigering van de makers om scenes 'na te spelen' en door het raadplegen van deskundigen tijdens het productieproces. De serie is in staat te voldoen aan haar doel om historische maatstaven te combineren met de conventies van televisie, ondanks de beperkte productie- en onderzoekstijd. De analyse laat zien dat om dit niveau te kunnen continueren, een televisieprogramma gebaat is bij 'expertise' op het gebied van onderzoek, regie en productie van een geschiedenisprogramma.

Vanuit de opvatting dat geschiedenis een continu proces is, is de institutionalisering van geschiedenisprogramma's op de Nederlandse televisie mede gewaarborgd door het ontstaan en in stand houden van deze 'huisstijl' of 'school'. Een 'huisstijl' omvat een gemeenschappelijke overtuiging van hoe je geschiedenis op broadcast televisie brengt. Door het geleidelijk opbouwen van expertise en intrinsieke samenwerking blijft deze deskundigheid ook binnenshuis, bijvoorbeeld door interne mobiliteit. Tegen deze achtergrond speelt de bedrijfsgeschiedenis van het Nederlandse publieke omroep systeem een belangrijke rol - aan de ene kant de uitdagingen die intrinsieke samenwerking tot stand brengen, en aan de andere kant de kans voor NTR (en eerder NPS) en VPRO om hun eigen autoriteit voorop te stellen bij het verbeelden van geschiedenis op televisie.

Geschiedenisprogramma's als Andere tijden verbinden kijkers met het verleden, bieden belangrijke contextuele kaders en laten zien dat het vertellen van verhalen en herinneringen via televisie onverminderd relevant is om gangbare interpretaties van geschiedenis uit te dagen. Wanneer komt een onderwerp in aanmerking om uitgezonden te worden in een op archiefbeelden gebaseerde geschiedenisserie op broadcast televisie, gebaseerd op de door Andere tijden gehanteerde strategieën? In het algemeen moet een historische vertelling ten minste een 'tweede laag'98 of toegevoegde waarde hebben. Dit houdt in dat het verhaal inclusief minder bekende, bijna vergeten of persoonlijke verhalen - meer moet inhouden dan het verhaal zelf: het verhaal moet aanvullende of nieuwe informatie geven over een bepaalde tijd of gebeurtenis. Een volstrekt incidenteel of individueel onderwerp zal daarom zelden worden vertoond, tenzij dit representatief is voor veel mensen in de samenleving. In de tweede plaats zijn op archiefbeelden gebaseerde geschiedenisseries in staat een 'spiegel' voor te houden en zodoende het verleden terug te projecteren. Op deze manier fungeert het televisieprogramma als het ware als een 'teletijdmachine'. Echter, zoals de analyse laat zien, biedt deze tijdmachine contextualisatie, reflectie en commentaar.

\section{Noten}

I. Dit artikel is een vertaling van delen uit: Berber Hagedoorn, Doing History, Creating Memory: Representing the Past in Documentary and Archive-Based Television Programmes within a Multi-Platform Landscape (Dissertatie Universiteit Utrecht, Utrecht, 20I6), I-90, in het bijzonder het hoofdstuk "The Poetics of Doing History on Broadcast Television: Andere Tijden”. Met dank aan Sonja de Leeuw, Eggo Müller en de anonieme reviewers voor hun feedback op een eerdere versie van dit onderzoek.

2. De kritiek bestaat onder meer uit dat televisie professionals niet de eisen van het vakgebied geschiedenis voorop zouden stellen, maar die van televisie maken; vragen bij de 'authenticiteit' en waarheidsclaim van audiovisueel materiaal; en vragen bij beperkingen van het medium, zoals beperkte tijd om een verhaal te vertellen. Zie: Brian Winston, “Combatting 'A Message without a Code': Writing the 'History' Documentary," in Televising History: Mediating the Past in Postwar Europe, ed. Erin Bell en Ann Gray (Basingstoke, Hampshire: Palgrave Macmillan, 2010), $42-58$. 
3. Onder andere: Jerome de Groot, Consuming History: Historians and Heritage in Contemporary Popular Culture (Londen: Routledge, 2009); Robert Rosenstone, History on Film / Film on History (Harlow: Pearson Education Limited, 2006); David Cannadine, History and the Media (Basingstoke, Hampshire: Palgrave Macmillan, 2004).

4. Onder andere: Amy Holdsworth, Television, Memory and Nostalgia (Basingstoke, Hampshire: Palgrave Macmillan, 20II); Erin Bell en Ann Gray, ed., Televising History: Mediating the Past in Postwar Europe (Basingstoke, Hampshire: Palgrave Macmillan, 20I0); Michelle Arrow, "Broadcasting the Past: Australian Television Histories”, History Australia 8, nr. I (20II): 223-46; Dafydd Sills-Jones, History Documentary on UK Terrestrial Television, I982-2002 (Dissertatie, University of Aberystwyth, 2009); Emma Hanna, The Great War on the Small Screen: Representing the First World War in Contemporary Britain (Edinburgh: Edinburgh University Press, 2009); Helen Wheatley, Re-Viewing Television History: Critical Issues in Television Historiography (Londen: I.B. Tauris, 2007); Tobias Ebbrecht, "History, Public Memory and Media Event: Codes and Conventions of Historical-Event Television in Germany”, Media History I3, nr. 2-3 (2007): 22I-34; Myra Macdonald, "Performing Memory on Television: Documentary and the ig6os", Screen 47, nr. 3 (2006): 327-45; Andrew Hoskins, "Television and the Collapse of Memory”, Time \& Society I3, nr. I (2004): I09-27; Gary R. Edgerton en Peter C. Rollins, eds., Television Histories: Shaping Collective Memory in the Media Age (Lexington, KY: University Press of Kentucky, 200I); Graham Roberts en Philip M. Taylor, The Historian, Television and Television History: A Collection (Luton: University of Luton Press, 200I).

5. Edward Hallett Carr, What Is History (Cambridge: Cambridge University Press, I96I), 30.

6. Aleida Assmann, "Re-Framing Memory: Between Individual and Collective Forms of Constructing the Past", in Performing the Past: Memory, History and Identity in Modern Europe, ed. Karin Tilmans, Frank van Vree en Jay Winter (Amsterdam: Amsterdam University Press, 2010), 35-50.

7. Zie bijvoorbeeld: John T. Caldwell, "Convergence Television: Aggregating Form and Repurposing Content in the Culture of Conglomeration", in Television after TV: Essays on a Medium in Transition, ed. Lynn Spigel en Jan Olsson (Durham, NC: Duke University Press, 2004), 57.

8. Christopher Anderson en Michael Curtin, "Writing Cultural History: The Challenge of Radio and Television," in Media History: Theories, Methods, Analysis, ed. Niels Brügger en Søren Kolstrup (Aarhus: Aarhus University Press, 2002), I7-I8. Zie ook: John Corner, Critical Ideas in Television Studies (Oxford: Oxford University Press, I999); John Hartley, Uses of Television (Londen: Routledge, I999).

9. Vanwege de nadruk op de inhoud en productie van dit Nederlandse programma als broadcast televisie worden de crossmediale en multiplatform aspecten van geschiedenistelevisie sinds 2000 niet behandeld, hiervoor verwijs ik naar mijn proefschrift, evenals voor de nadere analyse van Andere tijden sport: Hagedoorn, Doing History.

Io. Ann Gray en Erin Bell, History on Television (New York: Routledge, 2013).

II. Voor meer recente studies naar geschiedenis op televisie in Nederland en Vlaanderen in een breder historiografisch perspectief, zie: G. Janssen en A.-L. van Bruaene, "Historische televisieproducties," BMGN - Low Countries Historical Review I30, no. I (2015): 85-86; P. Knevel en J. Turpijn, “'Dat is wel eens anders geweest!' Geschiedenis op de Nederlandse televisie," BMGN - Low Countries Historical Review I30, no. I (2015): 87-Io6; H. Boers, J. Dobbels en I. Leonard, "Verhalen sprokkelen langs de frontlijn. Een kritische blik op Ten Oorlog," BMGN - Low Countries Historical Review I30, no. I (2015): I07-II9.

I2. David Bordwell, Poetics of Cinema (New York, NY: Routledge, 2008), I2.

I3. De cijfers weergegeven in de tabellen en figuren in $\$ 4$ zijn gebaseerd op een inhoudsanalyse van alle afleveringen van Andere tijden tussen maart 2000 en december 2016.

I4. Glen Creeber, "Case Study: Shot-by-Shot Analysis," in Tele-Visions: An Introduction to Studying Television, ed. Glen Creeber (Londen: British Film Institute, 2006), 43.

15. Lisa Gitelman, Always Already New: Media, History and the Data of Culture (Cambridge, MA: MIT Press, 2006), 8.

I6. De titel van het programma, Andere tijden, is bedacht door programmamaker Niels Cornelissen.

I7. “NPS Jaarverslag 2000" (Hilversum: NPS, 200I), 20.

I8. Ad van Liempt, persoonlijke communicatie, 30 juni 2016.

I9. Aanvankelijk werden er in een uitzending meestal meerdere onderwerpen behandeld, bijvoorbeeld in de eerste aflevering van I2 maart 2000.

20. Andere Tijden homepage, I3 februari 20I7, http://anderetijden.nl. Samen met het historische radioprogramma OVT (VPRO, I992-) vormde Andere tijden de belangrijkste basis voor de NPO Geschiedenis-website (voorheen Geschiedenis24 en /Geschiedenis), die later hernoemd is tot de huidige website anderetijden.nl en regelmatig voorzien wordt van aanvullend materiaal. De reden hiervoor is dat in het huidige omroepbestel het aantal 'kanalen' van de publieke omroep - inclusief websites bij televisieprogramma's - beperkt moet zijn. (Zie bijvoorbeeld: “Het publiek 
voorop: Concessiebeleidsplan 2016-2020" (Hilversum: NPO, 2015)). Vanaf februari 20II publiceert Historisch Nieuwsblad tevens artikelen die corresponderen met uitgezonden afleveringen van Andere tijden. Voormalige eindredacteuren Ad van Liempt en Carla Boos hebben daarnaast een serie boeken uitgegeven, gebaseerd op verhalen uitgezonden in en geplaatst op de website van Andere tijden: Ad van Liempt, red., Andere Tijden (Amsterdam: L.J. Veen, 2000); Ad van Liempt, red., Andere Tijden: Nieuwe verhalen over vroeger (Amsterdam: L.J. Veen, 200I); Ad van Liempt, red., Andere Tijden III: Nieuwe inzichten in oude kwesties (Amsterdam: L.J. Veen, 2002); Ad van Liempt, red., Andere Tijden IV: Sterke verhalen, die nog waar zijn ook (Amsterdam: L.J. Veen, 2003); Carla Boos, red., Andere Tijden V: Nieuw licht op oude kwesties (Amsterdam: L.J. Veen, 2004); Carla Boos, red., Andere Tijden VI: Nieuw licht op oude kwesties (Amsterdam: L.J. Veen, 2005); Carla Boos, red., Andere Tijden VII: Nieuw licht op oude kwesties (Amsterdam: L.J. Veen, 2006); Carla Boos, red., Andere Tijden VIII: Nieuwe verhalen over oude kwesties (Amsterdam: L.J. Veen, 2007); Carla Boos, red., Andere Tijden IX: Nieuwe verhalen over de actualiteit van gisteren (Amsterdam: L.J. Veen, 2008); Carla Boos, red., Andere Tijden X: Nieuwe verhalen over de actualiteit van gisteren (Amsterdam: L.J. Veen, 2009).

2I. "NPS Jaarverslag 200I" (Hilversum: NPS, 2002).

22. Ibid.; "NPS Jaarverslag 2002" (Hilversum: NPS, 2003); “NPS Jaarverslag 2003” (Hilversum: NPS, 2004); “NPS Jaarverslag 2004" (Hilversum: NPS, 2005); “NPS Jaarverslag 2005” (Hilversum: NPS, 2006); “NPS Jaarverslag 2006" (Hilversum: NPS, 2007); “NPS Jaarverslag 2007" (Hilversum: NPS, 2008); "NPS Jaarverslag 2008” (Hilversum: NPS, 2009); “NPS Jaarverslag 2009” (Hilversum: NPS, 2010); “NPS Jaarverslag 2010” (Hilversum: NPS, 2OII).

23. Henk Stouwdam, "Foekje Dillema wint wél op documentairefestival," NRC handelsblad, II oktober 2012.

24. "Sport ook zonder wedstrijden goed bekeken," ANP, 7 juli 2014.

25. "Kijkcijfers," Algemeen dagblad, I4 januari 2014.

26. "NTR Jaarverslag 20I5" (Hilversum: NTR, 20I6), 22.

27. “TV Kijkcijfers: Maand Top ıоo," Stichting Kijkonderzoek, januari 2017.

28. Karin van den Born, persoonlijke communicatie, 2I maart 2017.

29. "TV in Nederland 20I6" (Amsterdam: Stichting Kijkonderzoek, 20I7). https://www.kijkonderzoek.nl/images/ TV_in_Nederland/I70I30_SKO_TV_IN_NEDERLAND_20I6.pdf.

30. Zie ook: Berber Hagedoorn. "Towards a Participatory Memory: Multi-platform Storytelling in Historical Television Documentary," Continuum: Journal of Media a Cultural Studies, 29, no. 4 (2015): 579-592. doi: http://dx. doi.org/I0.1080/10304312.2015.1051804.

3I. Gerda Jansen Hendriks, "Zuiderzeeballade: een programma over de Nederlandse geschiedenis," november I992, p. 3. Intern document.

32. Raymond van den Boogaard, "Een hoekje voor het verleden," NRC handelsblad, II november I998, p. 29.

33. Ad van Liempt. Interview. Amsterdam, I2 mei 201 .

34. Ad van Liempt. Interview. Amsterdam, I2 mei $201 \mathrm{I}$.

35. Ad van Liempt. Interview. Amsterdam, I2 mei $201 \mathrm{I}$.

36. Van Liempt, "Het geheim van het historisch beeld."

37. Bert van der Veer, Go jaar televisie in Nederland (Baarn: Marmer, 20II), 216.

38. Het televisielandschap is hierbij aan een belangrijke verandering onderhevig geweest. Tot De slavernij, in 2OII gemaakt door de "Andere tijden-school", werd regelmatig nog deels geproduceerd met behulp van overheidsgeld. Omdat de regering sindsdien gestopt is met het rechtstreeks subsidiëren van televisieprogramma's, was dit voor nieuwe producties niet langer een mogelijkheid.

39. Ad van Liempt bestempelt zowel de berichtgeving over de inhuldiging van Koningin Wilhelmina in 1898 , als de meer recente historiografie over de dood van politicus Pim Fortuyn (gericht op de jaren 200I en 2002) als belangrijke uitzonderingen op deze regel. Van Liempt, "Het geheim van het historisch beeld."

40. Jansen Hendriks, "Zuiderzeeballade," I.

4I. Ad van Liempt. Interview. Amsterdam, I2 mei 20II.

42. Voor een andere aanpak, zie een overzicht van Nederlandse documentaires over de Tweede Wereldoorlog (tot I995) in: Chris Vos, Televisie en bezetting: een onderzoek naar de documentaire verbeelding van de Tweede Wereldoorlog in Nederland (Hilversum: Verloren, I995); Frank van Vree, "Televisie en de geschiedschrijving van de Tweede Wereldoorlog," Theoretische Geschiedenis, nr. 22 (I995): I-26.

43. Hagedoorn, Doing History, 86.

44. Karin van den Born. Interview. Hilversum, 5 oktober 2015.

45. Hagedoorn, Doing History, 85 . 
46. Ibid.

47. Karin van den Born. Interview. Hilversum, 5 oktober 2015.

48. Bill Nichols, Introduction to Documentary (Bloomington: Indiana University Press, 200I), I67.

49. Erin Bell, "Beyond the Witness: The Layering of Historical Testimonies on British Television," in Televising History: Mediating the Past in Postwar Europe, ed. Erin Bell en Ann Gray (Basingstoke, Hampshire: Palgrave Macmillan, 2010), 77 .

50. Ibid., 88.

51. Andere tijden heeft geëxperimenteerd met presentatie door Goedkoop op locatie, zie hiervoor de aflevering "Pantserwagens tegen kransen. Hannie Schaft-herdenking onder vuur" (NPS/VPRO, i6 april 2006).

52. Van Liempt, "Het geheim van het historisch beeld."

53. Gerda Jansen Hendriks, "Een voortzetting van de discussie over OVTV", I3 januari I999.

54. Ad van Liempt, “De Storia-notitie”, 2I juli I999, I, 3-4; Ad van Liempt, “Andere Tijden”, I november I999, I-4; Van Liempt, “Andere Tijden”, I november I999, 3.

55. Kees Ribbens, Een eigentijds verleden. Alledaagse historische cultuur in Nederland, 1945-2000 (Hilversum: Verloren, 2000), 283.

56. Gerda Jansen Hendriks. Interview. Hilversum, I6 mei 20II. Deze kritiek is interessant te noemen in vergelijking met het Zilveren Nipkowschijf Jury Rapport: 'Nooit heffen de programmamakers een vingertje of manen lessen te trekken uit het verleden. Er is geen sprake van moralisme maar "slechts" van pure feitenoverdracht. Historische journalistiek in de zuiverste soort en op een constant hoog niveau.' Zie: “Andere Tijden," Nipkowschijf homepage, I november 20II, http://www.nipkowschijf.nl.

57. Zie ook: John Corner, “'Once Upon a Time...' Visual Design and Documentary Openings,” in Televising History: Mediating the Past in Postwar Europe, ed. Erin Bell en Ann Gray (Basingstoke, Hampshire: Palgrave Macmillan, 20IO), I4-I5. 58. Maarten Nooter en Ad van Liempt, “Andere Tijden Sport, derde versie," 7 februari 2007, I. Bijvoorbeeld een interessante clip of foto aan het begin van het programma of een inzichtelijk filmpje van anderhalf tot twee minuten over de uit te zenden aflevering.

59. In Andere Tijden, aflevering “'De bezetting' van Loe de Jong”, reg. Femke Veltman. NPS/VPRO, 22 oktober 2009 .

6o. Maruša Pušnik, "Documentaries and Mediated Popular Histories: Shaping Memories and Images of Slovenia"s Past," in Technologies of Memory in the Arts, ed. Liedeke Plate en Anneke Smelik (Basingstoke: Palgrave Macmillan, 2009), I88-202; Anderson, "History TV and Popular Memory," 20.

6I. Gary R Edgerton, "Introduction: Television as Historian: A Different Kind of History Altogether," in Television Histories: Shaping Collective Memory in the Media Age, ed. Gary R. Edgerton en Peter C. Rollins (Lexington, KY: University Press of Kentucky, 200I), 4.

62. Gerda Jansen Hendriks. Interview. Hilversum, I6 mei 2011.

63. Bijvoorbeeld door historicus Loe de Jong.

64. Gerda Jansen Hendriks. Interview. Hilversum, I6 mei 201 .

65. Astrid Erll, Memory in Culture (Basingstoke: Palgrave Macmillan, 20II), I28.

66. Gerda Jansen Hendriks. Interview. Hilversum, I6 mei 201 I.

67. Leo Murray, "Clues in the Library: Fiction Techniques in the Non-Fiction Film Soundtrack Archive" (paper gepresenteerd op NECS Conference 'Archive of/for the Future', Łódź, Poland, I8 juni 20I5).

68. Gerda Jansen Hendriks. Interview. Hilversum, I6 mei 201 I.

69. Zie bijvoorbeeld: Gerda Jansen Hendriks, "How to Present Riots That Have Not Been Filmed", in The Historian, Television and Television History: A Collection, ed. Graham Roberts en Philip M Taylor (Luton: University of Luton Press, 200I), 55-6I.

70. Aangehaald in Andere Tijden, aflevering “De ondergang van de Junyo Maru”, reg. Ad van Liempt. NPS/VPRO, 25 februari 2003 .

7I. Ad van Liempt. Interview. Amsterdam, I2 mei 2011.

72. In Andere Tijden, aflevering "De ondergang van de Junyo Maru”.

73. Andere Tijden homepage, "De ondergang van de Junyo Maru", I3 februari 20I7, http://anderetijden.nl/ programma/I/Andere-Tijden/aflevering/5I5/De-ondergang-van-de-Junyo-Maru

74. Lizzy van Winsen. Interview. Utrecht, 20 mei 20I5; persoonlijke communicatie, 2I maart 2017.

75. John Durham Peters, "Witnessing," Media, Culture \& Society 23, nr. 6 (2001): 707. doi: http://dx.doi.org/ I0.II77/016344301023006002.

76. In Andere Tijden, aflevering “Oorlog in blik”, reg. Erik Willems. NPS/VPRO, ı6 september 20 Iо. 
77. In Ibid.

78. Kuhn, An Everyday Magic, 8-9.

79. Ibid.

8o. In Andere Tijden, aflevering "De ontvoering van Herrema", reg. Reinier van den Hout. NPS/VPRO, 2I oktober 20I0.

8I. Kuhn, An Everyday Magic, 8-9.

82. Ad van Liempt. Interview. Utrecht, 9 juni 20 II.

83. Misschien is er een uitzondering op deze Andere tijden-regel: de serie heeft geëxperimenteerd met verschillende vormen van vertellen. Bijvoorbeeld in de aflevering “Troelstra's tragedie” (NPS/VPRO, 20 september 2005) over de zogenaamde 'revolutie' van socialist Pieter Jelles Troelstra in I9ı8. De memoires van de overleden politici worden voorgelezen en uitgedragen door onder meer oud-premier Dries van Agt.

84. Hein Hoffmann. Interview. Hilversum, 5 oktober $201 \mathrm{I}$.

85. Ibid.

86. Gerda Jansen Hendriks. Interview. Hilversum, I6 mei 20II. Jansen Hendriks verwijst hier ook naar haar eigen academisch onderzoek naar de wetten van geschiedenisverhalen op televisie vertellen, zie: Gerda Jansen Hendriks, "How to Present Riots That Have Not Been Filmed," in The Historian, Television and Television History: A Collection, ed. Graham Roberts en Philip M. Taylor (Luton: University of Luton Press, 200I), 55-6I.

87. Gerda Jansen Hendriks, "Meer dan papier - het archief in Andere Tijden" (Lezing, KVAN studiemiddag 'Archieven en Journalistiek', Den Haag, I6 juli 2003).

88. Jaap de Moor, Generaal Spoor: triomf en tragiek van een legercommandant (Amsterdam: Boom, 20II).

89. In Andere Tijden, aflevering "Het optimisme van generaal Spoor", reg. Gerda Jansen Hendriks. NTR/VPRO, I4 mei 20II.

90. Gerda Jansen Hendriks. Interview. Hilversum, i6 mei $201 \mathrm{I}$.

9I. Ibid.

92. Brian Winston, Claiming the Real: The Documentary Film Revisited (Londen: British Film Institute, I995); Derek Paget, No Other Way to Tell It: Docudrama on Film and Television (Manchester: Manchester University Press, 20II), I45

93. Gerda Jansen Hendriks. Interview. Hilversum, i6 mei 20 II.

94. Ad van Liempt. Interview. Amsterdam, I2 mei 2011.

95. Ibid.

96. In het multiplatform tijdperk wordt deze cohesie verder uitgebuit bijvoorbeeld door hergebruik van onderzoek in online contexten, door programma's aan elkaar te linken en extra inhoud in digitale en (sociale) media omgevingen aan te bieden.

97. Zie ook: Berber Hagedoorn en Bas Agterberg, "The End of the Television Archive as We Know It? The National Archive as an Agent of Historical Knowledge in the Convergence Era," Media and Communication 4, no. 3 (20I6): I62-I75. doi: http://dx.doi.org/I0.I7645/mac.v4i3.595.

98. Ad van Liempt. Interview. Amsterdam, I2 mei $201 \mathrm{I}$.

\section{Bijlage: Overzicht Andere tijden afleveringen bij kwalitatieve tekstanalyse}

Andere tijden, geschiedenisprogramma, aflevering “Abraham Kuyper”, reg. Paul Ruigrok. NPS/VPRO, I2 maart 2000.

Andere tijden, aflevering "De Vondelstraat", reg. Gerda Jansen Hendriks. NPS/VPRO, I2 maart 2000.

Andere tijden, aflevering "Oudste films van Nederland", reg. Niels Cornelissen. NPS/ VPRO, 26 maart 2000.

Andere tijden, aflevering "Wim Kan", reg. Godfried van Run. NPS/VPRO, 2I mei 2000. Andere tijden, aflevering "De Beatles", reg. Ad van Liempt. NPS/VPRO, 5 oktober 2000. Andere tijden, aflevering "Molukse gijzeling in Assen", reg. René Roelofs. NPS/VPRO, 30 november 2000 . 
Andere tijden, aflevering "Woonwagenbewoners", reg. Yaèl Koren. NPS/VPRO, 2I december 2000.

Andere tijden, aflevering "De verloving van Beatrix en Claus", reg. Ad van Liempt. NPS/ VPRO, I5 februari 2001.

Andere tijden, aflevering "Het Boekenweekgeschenk van Reve", reg. Hein Hoffmann. NPS/VPRO, 8 maart 200I.

Andere tijden, aflevering "Tsjernobyl als Nederlandse ramp", reg. Yaèl Koren. NPS/ VPRO, 26 april 2001.

Andere tijden, aflevering "De spoorwegacties van zomer i96I", reg. Ad van Liempt. NPS/ VPRO, IO mei 200I.

Andere tijden, aflevering "De beginjaren van Pinkpop", reg. Har Tortike. NPS/VPRO, 3I mei 200I.

Andere tijden, aflevering "München”, reg. Matthijs Cats, Jan Eikelboom, Hein Hoffmann, Gerda Jansen Hendriks. NPS/VPRO, I8 september 200I.

Andere tijden, aflevering "50 jaar televisie", reg. Godfried van Run. NPS/VPRO, 2 oktober 200I.

Andere tijden, aflevering "Ik Jan Cremer", reg. Hein Hoffmann. NPS/VPRO, 6 november 200 I. Andere tijden, aflevering "Zo is het toevallig ook nog 's een keer", reg. Jahaga Bosscha. NPS/VPRO, 5 februari 2002.

Andere tijden, aflevering "Verkiezingsdebatten op televisie", reg. Paul Ruigrok. NPS/ VPRO, 23 april 2002.

Andere tijden, aflevering "Spetters, de wording van een cynisch sprookje", reg. Hein Hoffmann. NPS/VPRO, 24 september 2002.

Andere tijden, aflevering "DS'70", reg. Paul Ruigrok. NPS/VPRO, 29 oktober 2002.

Andere tijden, aflevering "Een Indische familie", reg. Gerda Jansen Hendriks. NPS/ VPRO, 5 november 2002.

Andere tijden, aflevering “Iо० ${ }^{\text {ste }}$ uitzending”, reg. Yaèl Koren, Matthijs Cats, Yfke Nijland, Gerard Nijssen. NPS/VPRO, I2 november 2002.

Andere tijden, aflevering “De 'vergeten' James Bond”, reg. Godfried van Run. NPS/ VPRO, I9 november 2002.

Andere tijden, aflevering "De ondergang van de Junyo Maru”, reg. Ad van Liempt. NPS/ VPRO, 25 februari 2003.

Andere tijden, aflevering "Gerbrandy in Londen", reg. Erik Willems. NPS/VPRO, I8 maart 2003.

Andere tijden, aflevering "Prinsjesdag I974: gijzeling Franse ambassade", reg. Hein Hoffmann. NPS/VPRO, I6 september 2003.

Andere tijden, aflevering "Begin van de TV", reg. Matthijs Cats. NPS/VPRO, 23 september 2003.

Andere tijden, aflevering "Bleekneusjes van I945", reg. Hein Hoffmann. NPS/VPRO, I4 oktober 2003.

Andere tijden, aflevering "Kennedy en de media", reg. Yaèl Koren. NPS/VPRO, I8 november 2003 . 
Andere tijden, aflevering "Floris", reg. Matthijs Cats. NPS/VPRO, 27 januari 2004. Andere tijden, aflevering "WK schaatsen", reg. Hein Hoffmann. NPS/VPRO, 3 februari 2004 .

Andere tijden, aflevering "De huwelijksreis van Juliana en Bernhard", reg. Matthijs Cats. NPS/VPRO, 23 maart 2004.

Andere tijden, aflevering "Oranje I974", reg. Paul Ruigrok. NPS/VPRO, 20 april 2004. Andere tijden, aflevering "Japan en judo", reg. Gerda Jansen Hendriks, Coby van Dijck. NPS/VPRO, I juni 2004.

Andere tijden, aflevering “Leni Riefenstahls 'Olympia”, reg. Coby van Dijck. NPS/VPRO, I2 augustus 2004 .

Andere tijden, aflevering “TV Io", reg. Hein Hoffmann. NPS/VPRO, 28 september 2004. Andere tijden, aflevering "Prins Bernhard", reg. Matthijs Cats, Gerda Jansen Hendriks. NPS/VPRO, 7 december 2004.

Andere tijden, aflevering "De komst van de moskee". NPS/VPRO, I februari 2005.

Andere tijden, aflevering "De RAF in Nederland", reg. Gerda Jansen Hendriks. NPS/ VPRO, I2 april 2005.

Andere tijden, aflevering "Duitse soldaten filmen in Nederland", reg. Matthijs Cats. NPS/ VPRO, IO mei 2005 .

Andere tijden, aflevering “Troelstra's tragedie”, reg. Gerda Jansen Hendriks. NPS/VPRO, 20 september 2005 .

Andere tijden, aflevering "Rembrandt in de oorlog", reg. Godfried van Run. NPS/VPRO, I2 maart 2006.

Andere tijden, aflevering "Pantserwagens tegen kransen. Hannie Schaft-herdenking onder vuur”, reg. Hein Hoffmann. NPS/VPRO, I6 april 2006.

Andere tijden, aflevering "Het proces van Neurenberg”, reg. Matthijs Cats. NPS/VPRO, 28 september 2006.

Andere tijden, aflevering "Rock \& roll in de polder", reg. Jan Kelder. NPS/VPRO, 5 oktober 2006.

Andere tijden, aflevering "Veertig jaar STER-reclame", reg. Yaèl Koren. NPS/VPRO, 4 januari 2007.

Andere tijden, aflevering "Race naar de maan", reg. Gerda Jansen Hendriks. NPS/VPRO, 25 januari 2007.

Andere tijden, aflevering "Martin Luther King”, reg. Yaèl Koren. NPS/VPRO, I5 maart 2007. Andere tijden, aflevering "Abortuswet”, reg. Paul Ruigrok. NPS/VPRO, 29 maart 2007. Andere tijden, aflevering "Hoek van Holland", reg. Carla Boos. NPS/VPRO, Io mei 2007. Andere tijden, aflevering "Spoedig naar huis. Nederlanders in de goelag”, reg. Matthijs Cats. NPS/VPRO, 29 november 2007.

Andere tijden, aflevering "Hollandscheveld", reg. Erik Willems. NPS/VPRO, 6 maart 2008. Andere tijden, aflevering "De andere familie Frank" reg. Erik Willems. NPS/VPRO, 4 mei 2008.

Andere tijden, aflevering "Parijs '68”, reg. Paul Ruigrok, Reinier van den Hout. NPS/ VPRO, 22 mei 2008. 
Andere tijden, aflevering "Victory Boogy Woogie", reg. Thomas Blom. NPS/VPRO, 4 september 2008.

Andere tijden, aflevering "Redt een kind", reg. Jan Eikelboom. NPS/VPRO, I8 december 2008.

Andere tijden, aflevering "Kennedy: een jonge president", reg. Jan Eikelboom. NPS/ VPRO, I5 januari 2009.

Andere tijden, aflevering "No Future", reg. Paul Ruigrok. NPS/VPRO, 29 januari 2009. Andere tijden, aflevering "Beach Boys in de polder", reg. Femke Veltman. NPS/VPRO, I9 februari 2009 .

Andere tijden, aflevering "De stem: Philip Bloemendal", reg. Erik Willems. NPS/VPRO, I2 maart 2009 .

Andere tijden, aflevering "Radio Oranje", reg. Tonko Dop. NPS/VPRO, 7 mei 2009.

Andere tijden, aflevering "De grootste familie van Nederland: de TROS", reg. Godfried van Run. NPS/VPRO, I oktober 2009.

Andere tijden, aflevering “'De bezetting' van Loe de Jong”, reg. Femke Veltman. NPS/ VPRO, 22 oktober 2009 .

Andere tijden, aflevering "De entree van Jan Peter Balkenende", reg. Reinier van den Hout. NPS/VPRO, I9 november 2009.

Andere tijden, aflevering "The making of Nelson Mandela", reg. Godfried van Run. NPS/ VPRO, II februari 2010.

Andere tijden, aflevering "De val van kabinet Lubbers II", reg. Gerda Jansen Hendriks, Reinier van den Hout, Paul Ruigrok. NPS/VPRO, 25 februari 2010.

Andere tijden, aflevering "Verboden voor Duitsers. Katendrecht in oorlogstijd", reg. Reinier van den Hout. NPS/VPRO, 29 april 2010.

Andere tijden, aflevering "Tuan Papa: liefde in tijden van oorlog”, reg. Annegriet Wietsma. NPS/VPRO, I juli 2010.

Andere tijden, aflevering "Oorlog in blik", reg. Erik Willems. NPS/VPRO, I6 september 2010.

Andere tijden, aflevering "Partij of principes", reg. Reinier van den Hout. NPS/VPRO, 23 september 2010.

Andere tijden, aflevering "De ontvoering van Herrema”, reg. Reinier van den Hout. NPS/ VPRO, 2I oktober 2010.

Andere tijden, aflevering "De ware soldaten van Oranje", reg. Gerda Jansen Hendriks. NPS/VPRO, 4 november 2010.

Andere tijden, aflevering "De explosieve idealen van RaRa. Deel ı: de Makro-branden", reg. Paul Ruigrok. NPS/VPRO, I8 november 2010.

Andere tijden, aflevering “De explosieve idealen van RaRa. Deel 2: de opsporing”, reg. Paul Ruigrok. NPS/VPRO, 25 november 2010.

Andere tijden, aflevering "Bureau Warmoesstraat. Deel I", reg. Paul Ruigrok. NTR/VPRO, 22 januari 201 I.

Andere tijden, aflevering "Bureau Warmoesstraat. Deel 2", reg. Paul Ruigrok. NTR/ VPRO, 29 januari $20 I I$. 
Andere tijden, aflevering "Zo en niet anders", reg. Reinier van den Hout. NTR/VPRO, 26 februari 20II.

Andere tijden, aflevering "De schrijftafelmoordenaar. Het showproces tegen Eichmann", reg. Reinier van den Hout. NTR/VPRO, 2 april $201 \mathrm{I}$.

Andere tijden, aflevering "De oorlog niet voorbij", reg. Paul Ruigrok. NTR/VPRO, 7 mei 2011.

Andere tijden, aflevering "Het optimisme van generaal Spoor", reg. Gerda Jansen Hendriks. NTR/VPRO, I4 mei $20 I I$.

Andere tijden, aflevering "Misdaad in Oss", reg. Godfried van Run. NTR/VPRO, I7 september 20II.

Andere tijden, aflevering "Rolling Stones in het Kurhaus. Jongens waren het", reg. Femke Veltman. NTR/VPRO, 24 september 2OII.

Andere tijden, aflevering "Wubbo: een Hollander in de ruimte", reg. Godfried van Run. NTR/VPRO, I8 december 20II.

Andere tijden, aflevering "Punk: van pret naar protest", reg. Marcel Goedhart. NTR/ VPRO, 8 april 2012.

Andere tijden, aflevering "Pim Fortuyn: A Dutch dandy", reg. Reinier van den Hout. NTR/VPRO, 6 mei 2012.

Andere tijden, aflevering "Vrouwen in het gewapend verzet", reg. Yaèl Koren. NTR/ VPRO, 20 mei 2012.

Andere tijden, aflevering "Kiezen in crisistijd", reg. Godfried van Run. NTR/VPRO, 2 september 2012.

Andere tijden, aflevering "Kabinet in crisis", reg. Paul Ruigrok. NTR/VPRO, 9 september 2012 .

Andere tijden, aflevering "Asbest: sluipmoordenaar uit Goor", reg. Marcel Goedhart. NTR/VPRO, I8 november 2OI2.

Andere tijden, aflevering "De komst van het schijfje", reg. Reinier van den Hout. NTR/ VPRO, I7 februari 2013.

Andere tijden, aflevering "Oranje en het oproer", reg. Erik Willems. NTR/VPRO, 2I april 20I3.

Andere tijden, aflevering “I948: leve de Koningin!”, reg. Femke Veltman. NTR/VPRO, 28 april 2013.

Andere tijden, aflevering "Koerier voor Portugal", reg. Paul Ruigrok. NTR/VPRO, I2 mei 2013.

Andere tijden, aflevering "House, pillen en extase", reg. Hein Hoffmann. NTR/VPRO, 26 mei 2013.

Andere tijden, aflevering "Floris; remake", reg. Matthijs Cats, Godfried van Run. NTR/ VPRO, 6 oktober 2013 .

Andere tijden, aflevering "Spektakel rond het Koninkrijk", reg. Gerda Jansen Hendriks. NTR/VPRO, 20 oktober 2013.

Andere tijden, aflevering “Nieuws: Kennedy vermoord!”, reg. Reinier van den Hout. NTR/ VPRO, I7 november 20I3. 
Andere tijden, aflevering "Het musical-avontuur op Broadway", regs. Yaèl Koren, Reinier van den Hout. NTR/VPRO, 5 januari 2014.

Andere tijden, aflevering "De grote leugen; de echtscheidingswet van I97I”, reg. Gerda Jansen Hendriks. NTR/VPRO, I2 januari 2014.

Andere tijden, aflevering "Han van Meegeren: meestervervalser", reg. Reinier van den Hout. NTR/VPRO, 30 januari 2014.

Andere tijden, aflevering "Het lelijke eendje van de televisie", reg. Reinier van den Hout. NTR/VPRO, I3 maart 20I4.

Andere tijden, aflevering "Een ongewenste CIA-agent", reg. Paul Ruigrok. NTR/VPRO, 27 maart 20I4.

Andere tijden, aflevering "Joop wil een soap", reg. Hein Hoffmann. NTR/VPRO, 25 september 2014 .

Andere tijden, aflevering "Ebola: de jacht op een dodelijk virus", reg. Hein Hoffmann. NTR/VPRO, 6 november 2OI4.

Andere tijden, aflevering "Witte Sjors en zwarte Sjimmie", reg. Reinier van den Hout. NTR/VPRO, I3 november 2014.

Andere tijden, aflevering "Levende memorie in Auschwitz", reg. Hein Hoffmann. NTR/ VPRO, 27 januari 2015 .

Andere tijden, aflevering "Jean Desmet, handelaar in dromen", reg. Hein Hoffmann. NTR/VPRO, 24 februari 2015 .

Andere tijden, aflevering "Het avontuur van de radiopiraten", reg. Yaèl Koren. NTR/ VPRO, I7 maart 20I5.

Andere tijden, aflevering "Geweld tegen conducteurs", reg. Reinier van den Hout. NTR/ VPRO, 2I april 20I5.

Andere tijden, aflevering “De Bevrijding nabij”, reg. Gerda Jansen Hendriks. NTR/VPRO, 28 april 2015 .

Andere tijden, aflevering "Drie keer bevrijd! De Bevrijding in iconische beelden", reg. Hein Hoffmann. NTR/VPRO, 5 mei 20I5.

Andere tijden, aflevering "Bouterse, het Haagse hoofdpijndossier", reg. Paul Ruigrok. NTR/VPRO, I9 mei 20I5.

Andere tijden, aflevering "Vrouwen aan de bal", reg. Reinier van den Hout. NTR/VPRO, 26 mei 2015.

Andere tijden special: WOII in amateurfilm, geschiedenisprogramma, reg. Ad van Liempt. NPS/VPRO, 4 mei 2004.

Andere tijden special: de andere jaren vijftig, reg. Hein Hoffmann. NPS/VPRO, 22 maart 2005.

Andere tijden special: tussen hoop en vrees, reg. Godfried van Run. NPS/VPRO, 4 juni 2006. Andere tijden special: van D-day tot de Dam, reg. Matthijs Cats. NPS/VPRO, 3 mei 2007. Andere tijden special: gezien ons eigen leven, reg. Yaèl Koren. NPS/VPRO, 7 september 2008.

Andere tijden special: 100 jaar Elfstedentocht, reg. Marnix Koolhaas, Dirk Jan Roeleven. NPS/VPRO, I januari 2009 . 
Andere tijden special: oorlog op komst, reg. Paul Ruigrok. NPS/VPRO, I8 oktober 2009. Andere tijden special: door soldatenogen, reg. Gerda Jansen Hendriks. NPS/VPRO, 27 december 2009 .

Andere tijden special: ode aan de rivier, reg. Godfried van Run. NPS/VPRO, 30 december 2010.

Andere tijden special: jaren van vooruitgang. Nederland tussen 1910 en 1920, reg. Matthijs Cats. NTR/VPRO, I5 mei $201 \mathrm{II}$

Andere tijden special: alles wordt anders. Nederland in de jaren 6o, reg. Yaèl Koren. NTR/ VPRO, 22 mei $201 \mathrm{II}$

Andere tijden special: van doarp en durp, reg. Femke Veltman. NTR/VPRO, 25 december $20 I I$. Andere tijden special: de verwarrende jaren 70, reg. Hein Hoffmann. NTR/VPRO, 30 december 2012.

Andere tijden special: de ballen van de jaren 80, reg. Matthijs Cats. NTR/VPRO, 26 december 2013 .

Andere tijden special: de dagen na Hitler, reg. Reinier van den Hout. NTR/VPRO, I8 december 20I4.

Andere tijden special: schitterende hoogmoed in de jaren 9o, reg. Yaèl Koren. NTR/VPRO, 30 december 2014 .

\section{Biografie}

Berber Hagedoorn is media- en cultuurwetenschapper en werkt als Assistant Professor Media Studies aan de Rijksuniversiteit Groningen en als Researcher in Residence bij het Nederlands Instituut voor Beeld en Geluid. Hagedoorn voert onderzoek uit met en naar (gedigitaliseerd) audiovisueel materiaal als cultureel erfgoed, met behulp van digitale data onderzoekstools. Momenteel voert zij onderzoek uit naar de verbeeldingskracht en representatiestrategieën van audiovisuele media bij media events, de eigen rol van mediaonderzoekers als verhalenvertellers, en hoe het samengaan van televisie met nieuwe, multiplatform mediatechnologieën de rol van televisie als link met het verleden heeft beïnvloed. Hagedoorn is vicevoorzitter van de ECREA Television Studies Thematic Section, en het dr. Catharine van Tussenbroek Fonds ter bevordering van de wetenschappelijke ontplooiing van vrouwelijk talent. 